\title{
Estudio interdisciplinario sobre los Sistemas de Valoración y Estándares Probatorios en el derecho procesal colombiano
}

\author{
Interdisciplinary study on valuation systems and evidentiary \\ standards in Colombian procedural law
}

\section{Estudo interdisciplinar sobre os sistemas de valoração da prova e os standards probatórios no direito processual colombiano}

\section{Francisco Javier Rivera-Olarte ${ }^{1}$ Lina Fernanda Rojas-Quinayá2}

Recibido: 5 de agosto de 2019 Aprobado: 18 de septiembre de 2019 Publicado: 5 de noviembre de 2019

Cómo citar este artículo: Francisco Javier Rivera-Olarte y Lina Fernanda Rojas-Quinayá. Estudio interdisciplinario sobre los Sistemas de Valoración y Estándares probatorios en el Derecho Procesal colombiano. DIXI 30, julio-diciembre 2019, 1-49. DOI: https://doi.org/10.16925/2357-5891.2019.02.01

Artículo de investigación. https://doi.org/10.16925/2357-5891.2019.02.01

1 Magíster en Derecho, programa de Derecho de los Recursos Naturales, Universidad Externado de Colombia; especialista en Derecho Probatorio, Universidad Católica; especialista en Derecho Administrativo, Universidad Libre, sede Bogotá; especialista en Pedagogía, Universidad de la Amazonia. Docente del Programa de Derecho adscrito a la Facultad de Derecho de la Universidad de la Amazonia.

ORCID: https://orcid.org/0000-0002-9685-5577

Correo electrónico: franciscorivera1975@gmail.com

2 Especialista en Derecho Constitucional, Universidad Libre, sede Bogotá; especialista en Derecho Público-Financiero, Universidad Libre; especialista en Derecho Administrativo, Universidad Libre; especialista en Derecho Probatorio, Universidad Católica; especialista en Pedagogía, Universidad de la Amazonia.

ORCID: https://orcid.org/0000-0002-1157-729X

Correo electrónico: linafercha80@gmail.com 


\section{Resumen}

Objetivo: el propósito de esta investigación es realizar un estudio interdisciplinario sobre el marco jurídico, doctrinal y jurisprudencial de los sistemas de valoración y los estándares de prueba en el derecho procesal colombiano, con el fin de determinar su aplicación por parte de los jueces al momento de fallar. Metodología: el desarrollo de la presente propuesta está enmarcada en el tipo de investigación jurídica toda vez que pretende, a partir de un estudio normativo e interdisciplinario (derecho procesal), revisar el tema de los sistemas de valoración y el estándar de prueba. Así mismo, está cimentada en el método deductivo y analítico-descriptivo; por último, la técnica aplicada es la documental bibliográfica.

Resultados y conclusiones: primero: en la actualidad, el derecho procesal probatorio está cimentado en "la sana crítica" como sistema de valoración de la prueba; segundo: en Colombia, el derecho probatorio penal, en el artículo 381 CPP, enuncia el estándar de prueba, consistente en el "conocimiento más allá de toda duda"; tercero: el derecho procesal en materia probatoria no desarrolló los elementos de la sana crítica, ni los estándares de prueba a aplicar, los cuales son normas vacías que requieren ser llenadas a través de la doctrina y la jurisprudencia.

Palabras clave: actividad probatoria, estándar de prueba, prueba, sistemas de valoración, valoración de la prueba.

\section{Abstract}

Purpose: The purpose of this research is to conduct an interdisciplinary study on the legal, doctrinal and jurisprudential framework of evaluation systems and standards of evidence in Colombian procedural law, in order to determine their application by judges at the time of adjudication.

Methodology: The development of the present proposal is framed in the type of legal research since it intends, from a normative and interdisciplinary study (procedural law), to review the subject of the valuation systems and the standard of evidence. Likewise, it is based on the deductive and analytical-descriptive method. Finally, the applied technique is the documentary technique.

Results and conclusions: First, nowadays, procedural law of evidence is based on "healthy criticism" as a system for evaluating the evidence. Second, in Colombia, the law of criminal evidence, in Article 381 of the Political Constitution, enunciates that the standard of proof consists of "knowledge beyond all doubt". Third, procedural law of evidence has not developed the elements of healthy criticism, nor the standards of proof to be applied, which are empty norms that need to be filled in through doctrine and jurisprudence.

Keywords: Evidentiary activity, test standard, test, assessment systems, test evaluation

\section{Resumo}

Objetivo: o objetivo desta pesquisa é realizar um estudo interdisciplinar sobre o referencial jurídico, doutrinal e jurisprudencial dos sistemas de valoração da prova e dos standards probatórios no direito processual colombiano, a fim de determinar sua aplicação por parte dos juízes no momento de dar a sentença.

Metodologia: o desenvolvimento desta proposta está delimitado no tipo de pesquisa jurídica, já que pretende, a partir de um estudo normativo e interdisciplinar (direito processual), revisar o tema dos sistemas de valoração e standard da prova. Além disso, está baseada no método dedutivo e analítico-descritivo; por último, a técnica aplicada é a documental bibliográfica. 
Resultados e conclusões: em primeiro lugar, na atualidade, o direito processual probatório está fundamentado na "crítica sadia" como sistema de valoração da prova; em segundo, na Colômbia, o direito probatório penal, no artigo 381 do Código de Processo Penal, enuncia o standard probatório, consistente no "conhecimento mais além de toda dúvida"; em terceiro, o direito processual, em matéria probatória, não desenvolveu os elementos da crítica sadia nem os standards probatórios a aplicar, os quais são normas vazias que requerem ser preenchidas por meio da doutrina e da jurisprudência.

Palavras-chave: atividade probatória, standards probatórios, prova, sistemas de valoração, valoração da prova.

\section{INTRODUCCIÓN}

La constitucionalización del derecho demanda hoy interpretar la ley a la luz de la Constitución Política (CP) (artículo 230), y verla de manera integral e interdisciplinaria con el resto del sistema jurídico colombiano (artículo 4 CP). A los conflictos de carácter jurídico hay que darles una solución ajustada a la realidad (verdad-certeza) conforme al derecho (leyes preexistentes), proporcionando plenas garantías a los litigantes (partes), y conforme a los procedimientos judiciales y las reglas propias de cada juicio (artículo 29 cP), procurando evitar acciones arbitrarias, irracionales o caprichosas al momento de valorarse la prueba y motivarse la sentencia por parte del juzgador (defecto fáctico). No es menos cierto que en la potestad legislativa² que la Carta superior otorga al Congreso para expedir códigos en todos los ramos de la legislación (artículo 150-2), entre ellos el procesal y la facultad de diseñar las reglas del debido proceso (artículo 29 CP), se debe observar y regular ciertas garantías mínimas en materia probatoria ${ }^{3}$.

Estas garantías mínimas probatorias están dadas a partir de la estructura probatoria del proceso (derecho procesal), conformada por los medios de prueba admisibles, las oportunidades que tienen los sujetos procesales para pedir pruebas, las

1 Eduardo J. Couture señala que el derecho procesal es la "rama del saber jurídico que estudia en forma sistemática la naturaleza del proceso [...] su constitución, desenvolvimiento y eficacia". Véase Enrique Véscovi. TEORía GeneraL DEL PROCESO. 2. ${ }^{a}$ edición. Editorial Temis. (2006). Pág. 8.

2 Id. "El Estado, en el desempeño de su función pública, regula las relaciones intersubjetivas mediante dos distintos órdenes de actividades. Con las primeras que es la legislación, establece las normas generales que deben regir esas relaciones. Con las segundas, que es la jurisdicción, se procura obtener la realización práctica de las primeras, declarando cuál es la ley del caso concreto (proceso de conocimiento) y adoptando medidas para que esas reglas sean cumplidas (proceso de ejecución)".

3 Corte Constitucional de Colombia. SENTENCIA C-1270 de 2000 (MP Antonio Barrera Carbonell; septiembre 20 de 2000). Disponible en: http://www.corteconstitucional.gov. co/relatoria/2000/C-1270-00.htm 
atribuciones del juez para decretarlas y practicarlas, la facultad oficiosa para producir pruebas y las reglas atinentes a su valoración. Así sucede con el derecho civil, laboral, administrativo, penal, etc., teniendo en cuenta que el derecho procesal es uno solo (unidad), respetando ciertas reglas especiales derivadas de cada una de las ramas del derecho.

En este orden, los jueces deben sustentar y motivar sus decisiones (sentencias) conforme a las pruebas regular y debidamente allegadas al proceso (artículo 164 CGP), acatando la apreciación de la prueba en conjunto, de acuerdo con las reglas de la sana crítica (sistema de valoración), y exponiendo razonadamente el mérito que le asigne a cada prueba (artículos 176 CGP; 61 CPTSS; 211 CPACA; 380 CPP), porque son estos los presupuestos o características que le permiten alcanzar cierto grado de certeza o umbral de conocimiento (estándar de prueba). Por ejemplo, en el área penal, el juez debe poseer un conocimiento para condenar "más allá de toda duda" (artículo 381 CPP). En materia de restitución de tierras -oposición- se debe probar la buena fe "exenta de culpa" (artículos 88, 91, 98 L. 1448/11).

Ahora bien, dichos mandatos propenden a que los jueces tomen sus decisiones ajustándose a la Constitución y la ley, garantizando así los derechos de las personas involucradas en cada juicio para que, durante su trámite, estos sean respetados de tal manera que se logre la correcta aplicación de la justicia ${ }^{4}$.

Hay que recordar que el fin de la actividad jurisdiccional (proceso) es: (I) la solución de los conflictos de carácter jurídico; y (II) la aplicación del derecho. Por lo tanto, toda decisión judicial debe apoyarse en pruebas (164 CGP), cuya finalidad es acreditar que aquello que se sabe, y por tanto se afirma, corresponde exactamente a la realidad (verdad-certeza). Dicho de otra manera, la prueba es la verificación o convencimiento al que llega el juez sobre la existencia de los hechos controvertidos a través de los medios de prueba (artículo 732 cPp). Si bien el convencimiento al que llega el juez tiene un carácter subjetivo -en cuanto se da dentro de un sujeto-, se manifiesta, sin embargo, en forma objetiva, en lo que se denomina motivación de la sentencia, en la que el juez debe expresar su juicio sobre los hechos, así como de las razones y argumentos con base en los cuales llegó a formarse tal juicio ${ }^{5}$, lo que incide en la recta administración de justicia.

4 Corte Suprema de Justicia. SENTENCIA STL 2673 de 2018 (MP Gerardo Botero Zuluaga; febrero 27 de 2018). Disponible en: www.cortesuprema.gov.co/corte/wp-content/ uploads/ relatoría/tutelas/B MAR2018/STL2673-2018.doc.

5 Véase Óscar Eduardo Henao Carrasquilla. código GENERAL DEL PROcESo. ANOTADo. Editorial Leyer. (2017). Pág. 216. 
Lo atrás señalado es la razón que motiva al Semillero de Investigación Juristas Amazónicos (SIJA), adscritos a la Facultad de Derecho de la Universidad de la Amazonia, sede Florencia-Caquetá, en la línea de Derecho Procesal, a presentar el proyecto de investigación Estudio interdisciplinario sobre los sistemas de valoración y estándares probatorios en el derecho procesal colombiano, con el fin de averiguar y determinar si los jueces de distinta naturaleza (derecho procesal como unidad) aplican un sistema de valoración y estándar de prueba al momento de resolver el litigio.

Como el objeto del presente estudio interdisciplinario son los sistemas de valoración y los estándares probatorios en el derecho procesal colombiano, los autores de este artículo se disponen a abordarlos a partir del marco jurídico que los regula, de los aportes de la doctrina y de la jurisprudencia colombiana, empleando la interacción de las distintas ramas del derecho procesal (verbigracia, procesal civil, procesal laboral, procesal administrativo y procesal penal).

Este documento está estructurado a partir de los siguientes objetivos: identificar qué es una prueba; establecer la valoración y los sistemas de valoración de la prueba describiendo sus características (apreciación en conjunto y sana crítica) y sus elementos (reglas de la experiencia, la lógica, la ciencia y la técnica); identificar el estándar de prueba y su clasificación; determinar la aplicación del sistema de valoración y los estándares de prueba por parte de los jueces de diferente naturaleza en sus decisiones.

El logro de los objetivos planteados en este documento se fundamenta en el tipo de investigación jurídica, toda vez que pretende, a partir de un estudio normativo e interdisciplinario (derecho procesal), abordar los sistemas de valoración y estándares de prueba. También se basa en el método deductivo, iniciando la investigación de marco general (Constitución Política) hasta llevarlo al caso concreto (sentencias de los jueces); y en el método analítico-descriptivo, porque permite observar y constatar, desde el contexto local, la aplicación del sistema y el estándar de prueba por parte de los operadores judiciales y con la técnica documental bibliográfica. Además, se realizó el trabajo de campo en la ciudad de Florencia-Caquetá revisando los fallos del primer trimestre del año 2019, así como encuestas a magistrados y jueces, en lo que se evidenció la prevalencia del sistema de valoración de sana crítica y el tipo de estándar.

Como resultado de la investigación, se logró establecer:

(I) que el sistema de valoración de la prueba aplicable por los jueces es la libre apreciación (sana crítica);

(II) la lógica y las reglas de la experiencia como elementos de la sana crítica son los más utilizados por los jueces para llegar a la certeza: 
(III) a pesar de que la Ley Procesal Probatoria (legislación civil, laboral, administrativo y penal) expresamente contempla el sistema de valoración de la libre apreciación de la prueba "sana crítica";

(IV) La Ley Procesal Probatoria expone los elementos integradores de la sana crítica; pero para su aplicación es necesario acudir a la jurisprudencia y a la doctrina como fuentes auxiliares de la actividad judicial (230 CP), toda vez que se guardó silencio respecto a los criterios a considerar;

(v) en cuanto al estándar de prueba, el derecho procesal probatorio en materia civil, laboral y contencioso administrativo no lo contempla; entre tanto, la ley procesal penal, en capítulo de pruebas, lo incorpora expresamente, estableciendo que el juez al momento de condenar requiere del conocimiento "más allá de duda razonable"; y en restitución de tierras, relacionado con el segundo ocupante, es necesario probar "la buena fe exenta de culpa";

(vı) al igual que con la valoración de la prueba, es necesario recurrir a la jurisprudencia y a la doctrina como fuentes auxiliares de actividad judicial por ser normas vacías;

(VII) si bien la norma procesal y los jueces manifiestan aplicar el sistema de valoración de sana crítica y como elementos prevalentes aplican reglas de la experiencia y la lógica, esto no se ve reflejado en las decisiones;

(VIII) los jueces y litigantes manifiestan no conocer los estándares de prueba aplicables a los procesos civiles, laborales y contenciosos administrativos;

(IX) en materia de restitución de tierras y en materia penal, es obligatorio la aplicación del estándar establecido en la Ley 1448 de 2011 y en la Ley 906 de 2004, en sus decisiones se evidencia la aplicación de los mismos;

(x) los estándares probatorios son un tema novedoso y poco abordado en Colombia.

A partir de la socialización y divulgación (publicación) de esta investigación, se espera impactar a la comunidad académica a nivel regional y local, y se pretende contribuir al direccionamiento y fortalecimiento de los planes de estudio de los programas de la Facultad de Derecho de la Universidad de la Amazonia (tanto del pregrado en los cursos de Formación, Lógica Jurídica, Interpretación y Argumentación Jurídica, Derecho Procesal y Probatorio, como en los cursos de Formación Pruebas en el Proceso Contencioso Administrativo y Régimen Sancionatorio Ambiental); y en los planes de estudio de los programas de Especialización en Contencioso Administrativo y en Derecho Ambiental, toda vez que inciden en el proceso de aprendizaje de los futuros profesionales del derecho. 


\section{ACTIVIDAD PROBATORIA EN EL DERECHO PROCESAL COLOMBIANO}

El hombre por el solo hecho de vivir en sociedad se ve enfrentado a un sinnúmero de problemas y conflictos de todo tipo, pero al derecho solo le interesan aquellos de relevancia jurídica (controversias), porque su finalidad reguladora es, precisamente, componer la litis.

Dicho de otro modo, la conducta humana está regulada por el derecho6, el cual recoge como norma la regla social, y al momento de presentarse un conflicto o al ser esta vulnerada por los asociados, deben ser solucionados por vía pacífica (proceso). El Estado debe garantizar la posibilidad de que cualquier persona solicite a los jueces competentes la protección, el restablecimiento de las situaciones jurídicas legítimas o la tutela jurídica de sus derechos, aplicando las normas jurídicas preexistentes (principio de legalidad) y empleando las formas propias de cada juicio (proceso), amparándose en el debido proceso (artículo 29 CP) 7.

Así las cosas, el Estado, en el desempeño de su función pública, regula las relaciones intersubjetivas mediante dos distintos órdenes de actividad8: la actividad legislativa y la actividad judicial.

La primera (actividad legislativa) está en cabeza del Congreso, facultado por la Constitución Política para expedir códigos en todos los ramos de la legislación (artículo 150-2 CP), entre ellos los del derecho procesal, por ejemplo: Código General del Proceso (CGP), Código Procesal del Trabajo y de la Seguridad Social (CPTSS), Código Procesal Administrativo y de lo Contencioso Administrativo (CPACA) y Código Procesal Penal (CPP), así como para diseñar las reglas del debido proceso (artículo 29 CP), con las cuales se debe observar y regular ciertas garantías mínimas; por ejemplo, en materia probatoria, el derecho a presentar pruebas y a controvertir las que se alleguen en su contra 9 .

Estas garantías mínimas probatorias están dadas a partir del derecho procesal -régimen probatorio-, el cual reglamenta la estructura probatoria del proceso, criterio aplicable a todos los ordenamientos procesales (civil, laboral, administrativo, penal, etc.) en cuanto a las reglas generales que son comunes conformadas por los

6 Enrique Véscovi, supra, nota 1. Pág. 1. Conjunto de normas de conducta que hacen posible la vida en común y resultan indispensables para su regulación.

$7 \quad l d$.

8 Id. Pág. 8

9 Corte Constitucional de Colombia. SENTEnCIA C-1270 de 2000 (MP Antonio Barrera Carbonell; septiembre 20 de 2000). Disponible en: http://www.corteconstitucional.gov. co/relatoria/2000/C-1270-00.htm 
medios de prueba admisibles (artículos 165 CGP; 51 CPTSS; 211 CPACA; 382 CPP); por las oportunidades que tienen los sujetos procesales para pedir pruebas (173 CGP; 145 CGPSS; 212 CPACA; 357 y 374 CPP); por las atribuciones del juez para decretarlas (272 CGP; 77 CPTSS; 180 CPACA; 356 y 357 CPP), admitirlas (169 CGP; 53 CPTSS; 214 CPACA; 376 CPP) y practicarlas (273 CGP; 77 y 80 CPTSS; 372 y SS CPP); por la facultad oficiosa para producirlas (169 y 170 CGP; 54 CPTSS; 213 CPACA), y por las reglas atinentes a su valoración (176 CGP; 60 y 61 CPTSS; 380 CPP), respetando las reglas específicas de cada medio de prueba según la rama del derecho y según el asunto (actividad probatoria) para una correcta (legal) prestación de la actividad jurisdiccional.

Y la segunda (actividad jurisdiccional) ${ }^{10}$ es la materialización de la primera (actividad legislativa), porque por medio de esta se puede reclamar la tutela jurisdiccional (aplicación del derecho), reconociendo como fines: (I) la solución de los conflictos de carácter jurídico para proteger o restablecer los derechos (civil, laboral, administrativo); y (II) aplicar el derecho (penal) ${ }^{11}$, permitiendo el acceso a la administración de justicia (artículo 229 CP) ${ }^{12}$, y prevaleciendo el derecho sustancial sobre el procesal (artículo $228)^{13}$. Es decir que el derecho procesal sirve como instrumento para la concreción y efectividad de las normas sustanciales. Precepto que es reiterado por el artículo 11 del CGP al indicar que "la interpretación de la ley procesal deberá tener en cuenta que el objeto de los procedimientos es la efectividad de los derechos reconocidos por la ley sustancial"14.

La jurisdicción es una sola unidad que aparece como función integradora del derecho, aunque reconociendo ciertas especialidades ${ }^{15}$, tal como se dejó planteado líneas atrás. Por lo tanto, no se limita a juzgar conflictos entre particulares solamente, sino también en lo penal, lo cual se manifiesta a través de la potestad sancionadora

10 Véase Eduardo J. Couture. Fundamentos del DereCho Procesal CIVIL. 3. ${ }^{\text {a }}$ edición. Roque Depalma Editores. (1958). Pág. 80.

11 Enrique Véscovi, supra, nota 1. Pág. 91.

12 Id.

13 "Cuando el artículo 228 de la Constitución establece que en las actuaciones de la Administración de Justicia 'prevalecerá el derecho sustancial', está reconociendo que el fin de la actividad jurisdicción, y del proceso, es la realización de los derechos consagrados en abstracto por el derecho objetivo, y, por consiguiente, la solución de los conflictos de intereses. Es evidente que, en relación con la realización de los derechos y la solución de los conflictos, el derecho procesal, y especialmente el proceso, es un medio". Véase Corte Constitucional de Colombia. SENTENCIA SU-913 de 2009 (MP Juan Carlos Henao Pérez; diciembre 11 de 2009). Disponible en: http://www.corteconstitucional.gov.co/relatoria/2009/SU913-09.htm

14 Ley 1564 de 2012. Por medio de la cual se expide el Código General del Proceso. Julio 12 de 2012. Do 48.489. Véase Ugo Rocco. TRATADO DE DERECHO PROCESAL CIVIL. TOMO I. Editorial Depalma. (1996). Pág. 48.

15 Enrique Véscovi, supra, nota 1. Págs. 101 y 104. 
al imputado, y en lo contencioso administrativo se juzgan las relaciones y conflictos entre los particulares y la propia administración ${ }^{16}$. Así las cosas, la jurisdicción (juez) actúa mediante un proceso ${ }^{17}$ que es el medio adecuado para resolver el litigio, que se desarrolla a través de una serie de etapas, ritualidades, reglas, actos y actividades desplegadas por las partes, y a través del cual el órgano jurisdiccional toma conocimiento del conflicto y sus particularidades.

Al respecto, resulta relevante tener en consideración que los hechos ocurren antes y fuera del proceso, siendo necesario, en consecuencia, que estos sean revelados dentro de él, lo que se logra a través de la actividad probatoria desarrollada por las partes. La prueba que cada uno de los litigantes aporte en el proceso será la que le permitirá al tribunal formarse una idea más o menos precisa de cómo se desencadenaron los hechos en realidad, "vislumbrándose con nitidez en esta etapa la íntima relación que existe entre proceso y verdad, [...] pues justamente es a través de la actividad probatoria desarrollada por las partes dentro del respectivo procedimiento que el tribunal puede llegar a obtener una cuota de verdad suficiente, que se acerque a la forma en que sucedieron los hechos en realidad y de esta manera llegar a la decisión más correcta"18.

Al respecto, la Corte Constitucional señala que el proceso se presenta como la suma de una serie de actos en la que concurren tres etapas de importancia: el momento cognitivo, que supone el conocimiento de los hechos y las demás circunstancias relevantes del conflicto; una instancia de evaluación de tales hechos, a la luz de las normas que se juzgan pertinentes para ello; y la decisión que se manifiesta en la parte resolutiva del fallo ${ }^{19}$.

16 Id. Págs. 5 y 6.

17 Id. Pág. 88. Véase también Corte Constitucional de Colombia. SENTENCIA C-548 de 1997 (MP Carlos Gaviria Díaz; octubre 30 de 1997). Disponible en http://www.corteconstitucional.gov.co/relatoria/1997/c-548-97.htm

18 Véase Nadia Paz Jara Astudillo y Cristián Andrés Vigneaux Ramírez. ESTÁNDAR DE PRUEBA EN EL PROCESO CIVIL. ESTUDIO SOBRE LOS TIPOS DE ESTÁNDAR DE PRUEBA Y SU NECESIDAD EN EL FUTURo PROCESO CIVIL CHILENo. Trabajo de grado. Universidad de Chile. (2017). Pág. 3.

19 Id. Véase también Ley 1437 de 2011. Por la cual se expide el Código de Procedimiento Administrativo y de lo Contencioso Administrativo. Julio 2 de 2011. Do 47.956. Artículo 179 (CPACA). 


\section{A. Etapas del proceso según la corte Constitucional de Colombia}

\section{Etapa cognitiva}

Esta primera etapa del proceso se despliega cuando una de las partes ejerce su derecho (poder) de acción ${ }^{20}$ poniendo en marcha, normalmente, la jurisdicción, con el fin de reclamar del órgano jurisdiccional (juez) la resolución de un conflicto de intereses (litigio) o la tutela de un determinado derecho, la cual se materializa ya sea a través de la demanda y su contestación (materia civil, laboral y administrativo) o a través de la acusación y defensa en el juicio oral (materia penal)21, según sea el caso.

Esta primera etapa es de suma importancia para las partes y para el juez. Para las primeras (las partes), porque radica en ellas establecer los puntos que son materia de controversia (iniciar el trámite judicial); es a donde deben llegar los medios de pruebas relevantes para la concesión de las pretensiones y alegar los supuestos fácticos que demuestren su hipótesis jurídica (artículos 82 y 96 CGP; 25, 31 y 70 CPTSS; 162 y 175 CPACA), es decir, sobre aquellos hechos controvertidos donde no hay acuerdo entre las partes, lo constituyen el objeto de la litis para su completo esclarecimiento (verdad) (artículos 372 y 373 CGP; 72 y 77 CPTSS; 180 CPACA), o los hechos o conductas consecutivas de un delito, su autor y las circunstancias agravantes o atenuantes, esto es, probar los elementos que constituyen el objeto de investigación, por ejemplo: homicidio, artículo 103; aborto, artículo 122; tortura, artículo 178; hurto, artículo 239 del Código Penal y artículos 2, 6, 336, 372, 366 y siguientes del CPP) ${ }^{22}$.

Ahora bien, de acuerdo con el sistema de la actividad procesal ("el mixto o el acusatorio"), las partes tienen la iniciativa y la carga probatoria, por lo tanto, no solo les corresponde a ellas proponer, aportar y/o solicitar pruebas observando las

20 Enrique Véscovi, supra, nota 1. Págs. 5 y 6. La moderna doctrina considera la acción como un derecho abstracto a reclamar la protección jurisdiccional, la cual se realiza por medio del proceso porque la actividad jurisdiccional no funciona - normalmente- de oficio, sino a iniciativa de parte.

21 Id. Pág. 6.

22 Véase Jaime Azula Camacho. MANUAL DE DERECHo PROCESAL. TOMO VI. PRUEBAS JUDICIALES. 4. ${ }^{a}$ edición. Editorial Temis. (2017). Pág. 38. Véase Hernán Fabio López Blanco. código general del PROCESo. PRUEBAS. DUPRE Editores Ltda. (2017). Págs. 73 y 74. 
oportunidades probatorias (artículos $173^{23}$ CGP; $145^{24}$ CPTSS; $212^{25}$ CPACA y los artículos 357 y $374^{26} \mathrm{CPP}$ ), sino también probar o acreditar los hechos que invocan a su favor y que sirven de base para sus pretensiones. Este deber, conocido bajo el aforismo "onus probandi", exige la realización de ciertas actuaciones procesales en interés propio, como la demostración de la ocurrencia de un hecho o el suministro de los medios de pruebas que respalden suficientemente la hipótesis jurídica defendida o la demostración de sus puntos de vista en relación con el objeto de la litis ${ }^{27}$.

Al respecto, el artículo 167 CGP, en armonía con los artículos 145 CPTSS (analogía), 211 CPACA (reenvío normativo), y 25 (integración normativa) y 378 (contradicción) del CPP, consagra el principio de la carga de la prueba, señalando que corresponde a las partes ${ }^{28}$ (en el procedimiento civil, laboral y administrativo-demandante-demandado y en el penal-Fiscalía-acusado) "probar el supuesto de hecho de

23 "OPORTUNIDAdES PROBATORIAS. Para que sean apreciadas por el juez, las pruebas deberán solicitarse, practicarse e incorporarse al proceso dentro de las oportunidades señaladas para ellos en este Código". Véase Ley 1564 de 2012. Por medio de la cual se expide el Código General del Proceso. Julio 12 de 2012. Do 48.489.

24 Teniendo en cuenta que la ley procesal no reguló las oportunidades probatorias para este caso, se aplicará por reenvío al Código General del Proceso tal como lo consagra el artículo 145 del CPTSS, el cual reza que: "APLICACIÓN ANALÓGICA. A falta de disposiciones especiales en el procedimiento del trabajo, se aplicarán las normas análogas de este decreto, y, en su defecto, las del Código General del Proceso". Véase DecretoLey 2158 de 1948. Por medio del cual se expide el Código Procesal del Trabajo y la Seguridad Social. Modificado por la Ley 712 de 2001. Diciembre 8 de 2001. Do 44.640.

25 "OPORTUNIDADES PROBATORIAS. Para que sean apreciadas por el juez las pruebas deberán solicitarse, practicarse e incorporarse al proceso dentro de los términos y oportunidades señalados en este Código. En primera instancia, son oportunidades para aportar o solicitar la práctica de pruebas: la demanda y su contestación; la reforma de la misma y su respuesta; la demanda de reconvención y su contestación; las excepciones y la oposición a las mismas; y los incidentes y su respuesta, en este último evento circunscritas a la cuestión planteada". Véase Ley 1437 de 2011. Por la cual se expide el Código de Procedimiento Administrativo y de lo Contencioso Administrativo. Julio 2 de 2011. Do 47.956.

26 "OPORTUNIDAD DE PRUEBAS. Toda prueba deberá ser solicitada o presentada en la audiencia preparatoria, salvo lo dispuesto en el inciso final del artículo 357, y se practicará en el momento correspondiente del juicio oral y público". Véase Ley 906 de 2004. Por medio de la cual se expide el Código de Procedimiento Penal. Septiembre 1 de 2004. DO 45.658.

27 Jaime Azula Camacho, supra, nota 22. Págs. 41 y 42 . Véase también Corte Constitucional de Colombia. SENTENCIA T-074 de 2018 (MP Carlos Libardo Bernal Pulido; marzo 2 de 2018). Disponible en: http://www.corteconstitucional.gov.co/relatoria/2018/t-074-18. htm\#_ftn77. Véase también Corte Constitucional de Colombia. SENTENCIA C-086 de 2016 (MP Jorge Iván Palacio Palacio; febrero 24 de 2019).

28 Corte Constitucional de Colombia. SENTENCIA C-209 de 2007 (MP Manuel José Cepeda Espinosa; marzo 21 de 2007). Disponible en: http://www.corteconstitucional.gov.co/ relatoria/2007/C-209-07.htm 
las normas que consagran el efecto jurídico que ellas persiguen", con el fin de salir victoriosas; no hacerlo se ubica en una situación de desventaja respecto a la sentencia.

Y para el segundo (juez), es importante porque es a través de la cual conoce los hechos; si es necesario, emplear los poderes que legalmente le fueron otorgados para lograr la tutela jurisdiccional efectiva, teniendo en cuenta las amplias facultades que posee para direccionar y decidir adecuadamente el asunto controvertido, y además, constituye el insumo fundamental para verificar las afirmaciones de los hechos expresados por las partes para producir o formar su convencimiento de la existencia de los hechos en controversia (verdad) con base en el juicio (actividad intelectual) que hace del material probatorio aportado, admitido, ordenado y recaudado oficiosamente (pruebas regular y oportunamente allegadas al proceso) para llegar a la certeza y poner fin al proceso (artículo 164 del CGP) ${ }^{29}$.

\section{Etapa de evaluación}

Teniendo en cuenta que este es el tema central del presente trabajo, el cual se desarrolla más adelante, tan solo se indicará que: la etapa final de la actividad probatoria es donde el juez ejerce su función oficiosa para la evaluación de los hechos controvertidos a la luz de las normas y pruebas que se reputan pertinentes para su resolución.

El juez goza de un manejo probatorio autónomo e independiente ${ }^{30}$, porque es la persona investida por el legislador para adelantar la discusión jurídica y, por ende, quien tiene la capacidad para apreciar con mayor grado de certeza los medios de prueba obrantes en el proceso ${ }^{31}$. Así las cosas, a pesar de que el juez goza de un amplio margen para valorar el acervo probatorio en el que cimienta su providencia, no puede utilizar sus facultades de manera irracional, caprichosa y arbitraria omitiendo así las garantías fijadas en el estatuto superior y la ley procesal.

La argumentación judicial de los hechos, es decir, la construcción de las premisas fácticas que fundamentan la decisión, a partir de la valoración del material probatorio, desconoce los cánones de la sana crítica (la lógica, la ciencia y la

29 Necesidad de la prueba. Toda decisión judicial debe fundarse en las pruebas regular y oportunamente allegadas al proceso. Las pruebas obtenidas con violación al debido proceso son nulas de pleno derecho.

30 Corte Constitucional de Colombia. SENTENCIA T-310 de 2009 (MP Luis Ernesto Vargas Silva; abril 30 de 2009). Disponible en: http://www.corteconstitucional.gov.co/relatoria/2009/T-310-09.htm

31 Corte Constitucional de Colombia. SENTENCIA T-074 de 2018 (MP Luis Guillermo Guerrero Pérez; marzo 2 de 2018). Disponible en http://www.corteconstitucional.gov. co/relatoria/2018/t-074-18.htm\#_ftn28 
experiencia), la objetividad, la legalidad o los parámetros mínimos de la argumentación judicial, lo que ocasiona que el funcionario adopte la decisión basado en elementos fácticos o normativos que resultan incomprensibles para los sujetos procesales involucrados 32 .

\section{Etapa resolutiva del fallo}

Esta etapa se refiere, en últimas, a la terminación del proceso (controversia o aplicación del derecho) que se plasma con el fallo o sentencia.

En ella se debe exponer el grado de convencimiento y las razones de su decisión, con lo que se materializa la valoración y el estándar de la prueba aplicado al caso concreto; es donde se presenta razonadamente el mérito que el juez le asignó a cada medio de prueba, la apreciación en la pluralidad de medios conjuntos (como un todo o unidad), inspirándose en los principios científicos que informan la crítica de la prueba y atendiendo las circunstancias relevantes del pleito y la conducta procesal observada por las partes.

La jurisprudencia constitucional acerca del deber de motivar las decisiones judiciales ha precisado que la exposición de las razones que llevaron a tomar una determinada decisión se erige como la mejor garantía para distinguir lo legal de lo arbitrario. Por ello, los jueces deben identificar en sus decisiones cuáles son las razones de hecho y de derecho que están empleando para la resolución de un caso, porque en un Estado social y democrático de derecho están prohibidas las decisiones basadas en el poder puramente personal y es apenas lógico que los operadores judiciales estén obligados a exponer de manera clara cuáles son las bases lógicas y silogísticas de sus fallos como prenda del efectivo imperio de la legalidad en el seno de la sociedad ${ }^{33}$.

Hay que tener en cuenta que el fin del proceso y de las pruebas es establecer la verdad a partir del hecho acreditado con los medios de prueba, es decir, que el juez puede llegar a la verdad o esclarecerla a partir del valor que tengan las pruebas oportunamente aportadas o solicitadas por las partes, las decretadas, admitidas y ordenadas por aquel, incluso las de oficio, salvo en materia penal, las practicadas y valoradas, según la naturaleza y el asunto de la controversia.

32 Corte Constitucional de Colombia. SENTENCIA SU-210 de 2017 (MP José Antonio Cepeda Amarís; abril 4 de 2017). Disponible en: http://www.corteconstitucional.gov.co/ relatoria/2017/SU210-17.htm

33 Corte Constitucional de Colombia. SENTENCIA T-237 de 2017 (MP Iván Humberto Escrucería Mayolo; abril 21 de 2017). Disponible en: http://corteconstitucional.gov.co/ relatoria/2017/T-237-17.htm 


\section{CONCEPTO DE PRUEBA}

La Constitución Política (artículo 29) consagra el derecho fundamental a la prueba, entregándole al ciudadano la facultad para acceder a la jurisdicción y oponerse si es el caso a las pretensiones que le formule al Estado o el Particular en las actuaciones públicas o privadas, o para pedir la protección frente a la amenaza o vulneración de un derecho fundamental mediante el uso de instrumentos indispensables para llegar a la verdad. La prueba es la razón, el argumento, el instrumento o el medio con el que se pretende demostrar o hacer presente al funcionario competente la verdad o falsedad de algo para que aplique determinada conciencia jurídica ${ }^{34}$.

Este derecho constitucional es desarrollado por el artículo 164 del CGP, que trae consigo que toda decisión judicial debe estar fundada en prueba regular y oportunamente allegada al proceso; y por el artículo 16 del CPP, cuyo precepto legal establece como regla que "será prueba solamente la que se produzca e incorpore en el juicio oral en forma pública, oral, concentrada y sujeta a confrontación y contradicción", en concordancia con el artículo 379 del estatuto en comento, el cual establece que el juez debe tener en cuenta como pruebas únicamente las que hayan sido practicadas y controvertidas en su presencia.

Las excepciones a la regla señalada están reguladas en el estatuto procesal penal y corresponden a la prueba anticipada (artículo 284 CPP) y a la prueba de referencia (artículos 437 y 438 ídem).

En relación con la actividad probatoria, en líneas atrás se indicó que

[...] los hechos ocurren antes y fuera del proceso, siendo necesario, en consecuencia, que estos sean revelados dentro de él, lo que se logra a través de la actividad probatoria desarrollada por las partes pues será la prueba que cada una de ellas aporte en el proceso la que permitirá al tribunal formarse una idea más o menos precisa de cómo se desencadenaron los hechos en realidad, vislumbrándose con nitidez en esta etapa la íntima relación que existe entre proceso y verdad, pues justamente es a través de la actividad probatoria desarrollada por las partes dentro del respectivo procedimiento, que el tribunal puede llegar a obtener una cuota de verdad suficiente, que se acerque a la forma en que sucedieron los hechos en realidad y de esta manera llegar a la decisión más correcta.

34 Véase Ana Giacomette Ferre. PARA LOGRAR LA TUTELA JURISDICCIONAL EFECTIVA EN LA PRUEBA EN LOS PROCESOS CONSTITUCIONALES. 2. ${ }^{\text {a }}$ edición. Señal Editorial y Ediciones Uniandes. (2009). Pág. 163. 
En la actividad probatoria, suelen distinguirse tres etapas: la producción, la asunción y la valoración, esta última consignada en materia civil en el artículo 167 del CGP ${ }^{35}$, en materia laboral en el artículo 61 CPTSS $^{36}$ y en materia penal en el artículo $380 \mathrm{CP}^{37}$. Estas disposiciones señalan claramente el sistema de apreciación de las pruebas, en materia civil es la sana crítica y en materia laboral es la libre formación del convencimiento con observancia en los principios científicos que informan la crítica de la prueba (sana crítica), y en materia penal tenemos la libre apreciación de la prueba.

La ley colombiana no trae una definición de prueba, pero sí la doctrina y jurisprudencia. A efectos de este documento, se abordarán las definiciones dadas por algunos tratadistas que correspondan al objeto de estudio así: la prueba es la demostración al juez de la verdad de un hecho o de un acto jurídico, utilizando medios calificados previamente por la ley como aptos, idóneos, adecuados, suficientes, conducentes, lícitos y pertinentes ${ }^{38}$. Devis Echandía entiende por prueba judicial las razones o motivos que sirven para llevarle al juez la certeza sobre los hechos ${ }^{39}$.

35 Ley 1564 de 2012. Por medio de la cual se expide el Código General del Proceso. Junio 12 de 2012. Do 48.489. Artículo 176: "Apreciación de la Prueba. Las pruebas deberán ser apreciadas en conjunto, de acuerdo con las reglas de la sana crítica, sin perjuicio de las solemnidades prescritas en la ley sustancial para la existencia o validez de ciertos actos. El Juez expondrá siempre razonadamente el mérito que le asigne a cada prueba".

Decreto 2158 de 1948. Por medio del cual se expide el Código Procesal del Trabajo y de la Seguridad Social sobre procedimientos en los juicios de trabajo. Julio 24 de 1948. Do 26773; modificado por la Ley 712 de 2001, del 8 de diciembre de 2001. Do 44.680. Artículo 61: "Libre formación del convencimiento. El Juez no estará sujeto a la tarifa legal de pruebas y por lo tanto formará libremente su convencimiento, inspirándose en los principios científicos que informan la crítica de la prueba y atendiendo a las circunstancias relevantes del pleito y a la conducta procesal observada por las partes. Sin embargo, cuando la ley exija determinada solemnidad ad substantiam actus, no se podrá admitir su prueba por otro medio. En todo caso, en la parte motiva de la sentencia el juez indicará los hechos y circunstancias que causaron su convencimiento".

37 Ley 906 de 2004. Por medio de la cual se expide el Código de Procedimiento Penal. Septiembre 1 de 2004. Do 45.658. Artículo 380: "Criterios de valoración. Los medios de prueba, los elementos materiales probatorios y la evidencia física, se apreciarán en conjunto. Los criterios para apreciar cada uno de ellos serán señalados en el respectivo capítulo".

38 Véase Jorge Cardozo Isaza. PRUEbas JUdiciales. 4. ${ }^{a}$ edición. Ediciones Librería del Profesional. (1982). Pág. 6.

39 Véase Hernando Devis Echandía. TEORía General DE LA PRUEBA PERICIAL. Biblioteca Jurídica Diké. (1987). Pág. 29. 


\section{VALORACIÓN DE LA PRUEBA}

Es una de las etapas del proceso y a su vez es la etapa final o fase culminante de la actividad probatoria, lo que la convierte en el resultado de todas las anteriores ${ }^{40}$. Es una función que le corresponde al juez de manera oficiosa para evaluar los hechos y demás circunstancias relevantes del conflicto a la luz de las normas y pruebas que se califican pertinentes para resolverlo; es lo que le permite al juez llegar a obtener una cuota de verdad suficiente; es acercarse a la forma en que sucedieron los hechos en realidad y de esta manera llegar a la decisión más correcta.

Dicha función se conoce, en su concepto básico, como "una operación intelectual realizada por el juez, destinada a establecer la eficacia o valor de las pruebas actuadas", apoyándose en las reglas de la sana crítica y en los principios científicos que informan la crítica de la prueba. De tal suerte, toda aquella prueba que fuere decretada y practicada conforme a la ley y en cumplimiento de sus requisitos legales (los referentes a la materia u objeto del proceso, constituidos bajo parámetros de conducencia u originalidad, necesidad, pertinencia, utilidad de la prueba y ausencia de prohibición legal) debe ser considerada en la presentación y contenido de la sentencia o decisión que pone fin a determinada instancia judicial, en pro de finiquitar el conflicto en discusión, a través del reconocimiento del derecho objetivo y sustancial que le merece cada caso en concreto.

La valoración de la prueba está íntimamente relacionada con el convencimiento, verdad o certeza, porque precisamente es a la que debe llegar el juez, previa observancia de las oportunidades probatorias y aplicación de los principios de apreciación ${ }^{41}$ y unidad de la prueba ${ }^{42}$.

40 Jaime Azula Camacho, supra, nota 22. Pág. 60. "Etapas de la Actividad Probatoria: Producción: es el conjunto de actuaciones que cumplen los diferentes sujetos a fin de incorporar al proceso las pruebas tendientes a establecer los hechos de controversia, esta etapa a su vez se subclasifica en averiguación o investigación, aseguramiento, proposición, ordenación y práctica; Asunción: desde el punto de vista jurídico, [...] es el conjunto de operaciones sensoriales e intelectivas que realiza el juzgador para conocer los hechos materia de la prueba. Entonces, en el testimonio, por ejemplo, se concreta a escuchar la recepción, o sea, las preguntas y respuestas, para formarse de estas un concepto sobre los hechos expuestos. Elemento o factor esencial para la asunción es la inmediación de la prueba; Valoración: valorar, en su acepción corriente es establecer el grado de utilidad o aptitud de una cosa para un determinado objetivo. Referido a la prueba, es el grado de convicción o credibilidad que produce en el juzgador. Mediante la valoración el juez concluye si los hechos materia de la controversia están o no demostrados".

41 Véase Jairo Parra Quijano. MANUAL DE DERECHO PROBATORIO. 10. ${ }^{\text {a }}$ edición ampliada y actualizada. Librería Ediciones del Profesional Ltda. (1999). Pág. 6.

42 Id. Véase también Jaime Azula Camacho, supra, nota 22. Pág. 7. 
Hay que dejar sentado que el conocimiento acerca de los hechos, que se logrará mediante la actividad probatoria, en ningún caso será completo, logrando obtener una fracción o porción de verdad: aquella que las partes quieren que se conozca. Es aquí donde se justifica el deber del juez en decretar oficiosamente las pruebas necesarias para el completo esclarecimiento de los hechos objeto de controversia, de conformidad con el artículo 170 del CGP y el artículo 54 del CPTSS.

La valoración de la prueba no puede ser caprichosa, irracional o arbitraria, y se presenta cuando el juez simplemente ignora la prueba u omite su valoración o cuando sin razón valedera no da por probado el hecho o la circunstancia que de la misma emerge clara y objetivamente; así las cosas, se configura un defecto fáctico tanto en su dimensión positiva como negativa ${ }^{43}$. Al contrario, la valoración debe ser el resultado juicioso, serio, objetivo y razonado de los hechos y del examen del acervo probatorio utilizando las reglas de la sana crítica y sus elementos que la integran (reglas de la experiencia y la lógica).

Al respecto, la Corte Constitucional en diferentes pronunciamientos ${ }^{44}$ señaló que si bien el juzgador tiene un gran poder de discrecional para valorar el material probatorio en el cual debe fundar su decisión y formar libremente su convencimiento, debe hacerlo inspirándose en los principios científicos de la sana crítica. Dicho poder jamás puede ser arbitrario; su actividad evaluativa probatoria supone necesariamente la adopción de criterios objetivos, racionales, serios y responsables.

\section{A. Definición de valoración de la prueba}

\section{Valoración de la prueba según la legislación colombiana (derecho procesal probatorio)}

La legislación colombiana, en el régimen probatorio, no contempla concepto alguno sobre la valoración de la prueba, además de que es un hecho propio de la doctrina y jurisprudencia. Por ello, se entra a revisar algunas definiciones doctrinarias tanto internacionales como nacionales, así como desde la jurisprudencia colombiana.

43 Hay jurisprudencia reiterada respecto al "defecto fáctico o falso raciocinio". Véase Sentencias T-442 de 1994; T-237 de 2017; T-164 de 2018.

44 Corte Constitucional de Colombia. SENTENCIA T-442 de 1994 (MP Antonio Barrera Carbonell; octubre 11 de 1994). Disponible en: http://www.corteconstitucional.gov. co/relatoria/1994/t-442-94.htm. Véase también Sentencias T-118 de 2013; T-064 de 2015; T-270 de 2017; T-237 de 2017. 


\section{Valoración de la prueba según la doctrina}

\subsection{Internacional}

La valoración de la prueba se ha definido como "un proceso intelectual realizado por el sentenciador y mediante el cual busca extraer, en la medida de lo posible, la verdad (relativa) existente detrás de los medios de prueba incorporados en la causa"45; En otras palabras, "se refiere a la determinación del apoyo empírico que los elementos de prueba aportados proporcionan a las hipótesis sobre los hechos del caso que se enfrentan en el proceso"46.

Según Gascón, la valoración de la prueba es el juicio de aceptabilidad de las informaciones aportadas al proceso a través de los medios de prueba ${ }^{47}$. Valorar consiste en evaluar o estimar si las afirmaciones de los hechos controvertidos por las partes (hipótesis) a través de los medios de prueba se pueden tomar por ciertas (verdaderas).

La valoración de la prueba es el juicio de aceptabilidad de las informaciones aportadas al proceso a través de los medios de prueba. Más exactamente, valorar consiste en evaluar si esas afirmaciones (en rigor, hipótesis) pueden aceptarse como verdaderas.

\subsection{Nacional}

Según Devis Echandía, "por valoración o apreciación de la prueba judicial se entiende la operación mental que tiene por fin conocer el mérito o valor de convicción que pueda deducirse de su contenido"48. A su vez, Paul Paredes indica que: "La apreciación o valoración es el acto del juez consistente en medir la eficacia probatoria de cada medio de prueba, o de su conjunto, según el precio o valor que le asigna la ley o le otorgue el juez, en relación al grado de convicción que permita generar certeza en el juez de la

45 Véase Roberto van Hasselt Garrido. EL ESTÁNDAR DE PRUEBA EN MATERIA INFRACCIONAL. ANÁLISIS JURISPRUDENCIAL. Centro de Estudios Tributarios Universidad de Chile. (2015). Pág. 213.

46 Véase Daniela Accatino. Certezas, dudas y propuestas en torno a estándar de prueba penal. REVISTA DE DERECHO DE LA PONTIFICIA UNIVERSIDAD CATÓLICA DE VALPARAíSO 48. (2011). Pág. 485.

47 Véase Marina Gascón Abellán. PRUEBA JUdICIAL: VALORACIÓN RACIONAL Y MOTIVACIÓN. Universidad de Castilla-La Mancha. (2012). Pág. 9. Disponible en: http://www.uclm.es/ posgrado.derecho/02/web/materiales/filosofia/Prueba.pdf

48 Véase Hernando Devis Echandía. COMPENDIO DE LA PRUEBA JUDICIAL. TOMO I. RubinzalCulzoni Editores. (2000). 
ocurrencia del hecho a probar"49. Y para Azula Camacho, "referido a la prueba, es el grado de convicción o credibilidad que produce en el juzgador. Mediante la valoración, el juez concluye si los hechos materia de controversia están o no demostrados"50.

Es aceptar o no la tesis o teoría del caso presentado por las partes, acción encaminada a demostrar la veracidad de los hechos usando los medios de prueba o conocimiento (artículos 165 CGP; 51 CPTSS; 211 CPACA; 382 CPP); verbigracia, instrumentos, métodos, personas o cosas que puedan proporcionar información útil para demostrar las afirmaciones de las cuales se sirve el juez para decidir respecto a la verdad o falsedad de los enunciados fácticos ${ }^{51}$. Es la estimación que el juez les da a los objetos en relación con los hechos en controversia para llegar, en la medida de lo posible, a la verdad de lo que realmente sucedió. Entonces, el objetivo que se busca con la valoración de las pruebas es el propio fin de la prueba, que es que se convenza al juez de los hechos que se alegan.

Teniendo en cuenta lo planteado por diferentes tratadistas, incluyendo la postura de los autores de este trabajo, se puede colegir que si bien a través de la valoración de la prueba el juez puede establecer el mérito de las pruebas, el grado de convicción alcanzado, la eficacia de las pruebas o la certeza sobre la existencia u ocurrencia de los hechos, no es menos cierto que el juez en su decisión (sentencia) debe motivar o explicar los esquemas racionales que le permitieron determinar el grado de convicción de las hipótesis del hecho y si estas podrían ser eventualmente verdaderas dentro del marco del proceso ${ }^{52}$.

Para dar cumplimiento a esta obligación, existen diversos sistemas de valoración de la prueba, los cuales a su vez cuentan con unas características, particularidades y elementos que justan su aplicación.

\section{B. Sistemas de valoración de la prueba}

Los sistemas de valoración de la prueba resultan ser los medios idóneos de justificación y argumentación de las decisiones judiciales en sus diversas instancias.

49 Véase Juan Linares San Román. LA VALORACIÓN DE LA PRUEBA. Blog Derecho y Cambio Social. (s. f.). Disponible en: http://www.derechoycambiosocial.com/revista013/laprueba.htm.

50 Jaime Azula Camacho, supra, nota 22. Pág. 64.

51 Véase Michele Taruffo. ALgUNAS CONSIDERACIONES SOBRE LA RELACIÓN ENTRE PRUEBA Y VeRdAD. LA PRUEBA. Editorial Metropolitana. (2008). Pág. 49. Disponible en: http:// letrujil.files.wordpress.com/2012/01/la-prueba-michele-taruffo.pdf

52 Corte Constitucional de Colombia. SENTENCIA T-237 de 2017 (MP Iván Humberto Escrucería Mayolo; abril 21 de 2017). Disponible en: http://corteconstitucional.gov.co/ relatoria/2017/T-237-17.htm 
Tratándose de la actividad valorativa, esta implica la interpretación jurídica que se genera como resultado de la práctica idónea y oportuna de los medios de prueba disponibles y acertados para cada proceso en concreto, esto sin olvidar las particularidades con que nacen los conflictos jurídicamente relevantes ${ }^{53}$ y la operación intelectual que hace el juez.

\section{Sistemas de valoración de la prueba según la legislación colombiana}

El derecho procesal colombiano, en el régimen probatorio (civil, laboral, administrativo, penal), contempla expresamente como sistema de valoración la libre apreciación, la cual señala los criterios orientadores que el juez debe aplicar al momento de valorar los medios probatorios allegados y aportados por las partes de manera regular y oportuna, así como las pruebas admitidas, producidas oficiosamente y practicadas por aquel, que son la base para formar su convencimiento acerca de la existencia (certeza) de los hechos y la edificación de la decisión (sentencia).

Estos criterios están dados por la apreciación en conjunto de las pruebas y las reglas de la sana crítica, los cuales son el respaldo de los principios de libre apreciación y unidad de la prueba, regulados en los artículos 176 del CGP; 60 y 61 del CPTSS; 211 del CPCA; y 380 y 381 del CPP, según los cuales es llevado a cabo por el juez que conoce de determinado asunto, toda vez que de ellos depende el grado de convicción y la exposición motivada de la decisión que se considere justa e imparcial para las partes y, en consecuencia, para la terminación del proceso.

\section{Sistemas de valoración de la prueba según la doctrina}

Algunos sectores de la doctrinaria ${ }^{54}$ reconocen dos sistemas opuestos para valorar la prueba: el de la tarifa legal y el de la libre formación del convencimiento, también

53 "La valoración reviste una importancia primordial, toda vez que constituye el eje central alrededor del cual gira el conjunto de actividades probatorias y buena parte de las garantías procesales. La estimación de los elementos de juicio aportados es la gran plataforma sobre la cual se erige la aplicación de los criterios decisionales. De ninguna manera puede asumirse que eso se proyecte sin contar con, $o$ al margen de, inferencias y argumentaciones correctas, condición para que pueda considerarse que se trata de una decisión judicial razonada, es decir, basada en razones articuladas que sirvan de premisas para las conclusiones que de ellas se deriven". Véase Jairo Iván Peña Ayazo. PRUEBA JUDICIAL: ANÁLISIS Y VALORIZACIÓN. Consejo Superior de la Judicatura, Escuela Judicial Rodrigo Lara Bonilla. (2008).

54 Véase Jairo Parra Quijano. MANUAL DE DERECHO PROBATORIO. 18. a edición. Librería Ediciones del Profesional Ltda. (2011). Pág. 215. Véase también Jaime Azula Camacho, supra, nota 22. Pág. 64. 
denominada "libre convicción", "libre apreciación" o "apreciación racional", nombres que dependen del doctrinante que se consulte, pero cuya esencia es la misma. Por ejemplo, Parra Quijano expresa que "si el juez puede y debe libremente valorar la prueba, estamos frente al sistema de la libre valoración (o libre convicción); cuando el legislador señala el valor de la prueba, estamos frente al sistema de la tarifa legal"55.

Hay otro sector de la doctrina ${ }^{56}$ que reconoce -además de la tarifa legal y la apreciación racional que contiene como criterio adjunto la apreciación en conjunto y la sana crítica ${ }^{57}$ - un tercer sistema: la íntima convicción.

Al respecto, los jueces consultados de la ciudad de Florencia-Caquetá contemplan que conocen dos sistemas de valoración: la libre determinación (que comprende a su vez la valoración en conjunto y la sana crítica, las cuales son las más aplicables en sus decisiones) y en algunos casos la tarifa legal, teniendo en cuenta que hay un rezago de este en el sistema jurídico colombiano.

No obstante, para este artículo es imprescindible identificar y definir los sistemas de valoración o apreciación de la prueba, indicando sus elementos integradores, con el fin de dar respuesta al objeto de investigación, y por el desarrollo teórico y práctico que ha tenido este tema en el ejercicio de la actividad probatoria. Los autores han identificado tres sistemas de valoración: tarifa legal, íntima convicción y libre apreciación.

\subsection{Tarifa legal}

La tarifa legal, también conocida como prueba legal o tasada, tuvo importancia en el sistema jurídico colombiano ${ }^{58}$ que estuvo influenciado por el derecho germánico desde sus primeras apariciones hasta hace algunos años; incluso podríamos afirmar que en la actualidad todavía quedan vestigios en su aplicación. Este sistema consiste en que el legislador establece previamente cuál es el valor probatorio que el juez deberá dar a cada uno de los medios de prueba practicados, es decir, el valor de la

55 Id.

56 Véase Leonel Gustavo Cáceres. EL falso RACIOCINIO, QUEBRANTAMIENTO DE LA SANA CRítICA. Ediciones Jurídicas Gustavo Ibáñez Ltda. (2005). Págs. 41-42.

57 Jaime Azula Camacho, supra, nota 22. Pág. 64.

58 Colombia, a través de la Ley 105 de 1931, adoptó el Código Judicial, en el cual se aplicó el sistema de la tarifa legal, en su artículo 697, al regular los testigos contestes, lo cual consiste en que si dos declaraciones coincidían en las circunstancias de lugar, tiempo y modo, el juez les otorgaba absoluta credibilidad, por considerarla plena prueba. 
prueba está predeterminado en la ley ${ }^{59}$; por tanto, el juez de manera anticipada conoce el grado de eficacia que debe atribuir a determinada evidencia, sin dejar espacios a la subjetividad y sin existir mayores libertades a la hora de apreciarlas; además debe ser acatado por este en sus decisiones:

Según Iglesias (1995:44), en este sistema es el legislador el que, partiendo de supuestos determinados, fija de modo abstracto la manera de apreciar determinados elementos de decisión, separando esta operación lógica de aquellas que el juez debía realizar libremente por su cuenta [y] el hecho de apartarse de la valoración ordenada por la norma jurídica le hacía incurrir en un error de derecho en la apreciación de la prueba, Ilamada falso juicio de convicción en nuestro sistema; el Juez en su trabajo de abstracción realiza una operación netamente aritmética, contando los medios de prueba y no sopesando su contenido60.

Pues bien, el hecho de que el juez esté obligado a valorar las pruebas de acuerdo con los extremos o pautas predeterminadas por el legislador y los medios de prueba fijados taxativamente en la norma jurídica, pero no poderla apreciar de manera libre en el juicio, llevó a que este sistema perdiera su valor y validez tanto para su eficacia en el proceso, como para llegar a la verdad.

\subsubsection{Características}

El valor de cada medio de prueba se encuentra establecido por la ley en forma permanente, invariable e inalterable; b) Les permite a las partes saber de antemano cuál es el valor que se les debe dar a las pruebas que se aportan o que se practican en el proceso; c) Habrá uniformidad en las decisiones judiciales; d) Evita que el Juez por cuestiones personales favorezca a alguna de las partes, ya que, basándose en el valor preestablecido por el legislador, no habrá lugar a subjetividades; e) impide el rechazo injustificado o arbitrario de medios de prueba aportados al proceso; f) El deber del juez es acatar y aplicar el valor de la prueba, no da

59 Id. Artículo 721. Al indicar que el dictamen pericial uniforme, explicado y debidamente fundamentado de dos peritos, es plena prueba, de igual manera con confesión judicial según el artículo 606.

60 Id. Págs. 41-42. 
lugar a la apreciación libre de la prueba; g) Suple la ignorancia y falta de experiencia de los jueces, ya que las normas redactadas por el legislador son hechas por personas doctas en el derecho6l.

A manera de ejemplo, dos testigos hacían plena prueba ${ }^{62}$.

\section{2 Íntima convicción}

También conocido como el íntimo convencimiento, aquí el juez está facultado para estimar las pruebas de manera libre, no observa restricciones ni sujeción a la norma legal; la motivación está afincada en su discurso íntimo, luego no está obligado a esbozar su motivación. De igual manera, es definido como "aquel en que el adjudicador cuenta con márgenes de libertad más amplios en todo lo referente a la etapa probatoria, vale decir, en cuanto a la elección de los medios de prueba, su producción, su apreciación, entre otros aspectos. En este sentido no se debe confundir la íntima convicción con la libre convicción o libre valoración de la prueba, pues esta última comporta formar su convicción usando la lógica, y las reglas de la experiencia"63.

Clariá Olmedo64, en su famosa obra Derecho procesal penal, señala que con este sistema "se da predominio al sentimiento sobre la razón, mejor aún, la intuición sobre la ciencia y la técnica"; y agrega que "no se excluye la posibilidad de una crítica racional. Pero esta, en realidad, queda sofocada en el fuero íntimo del juzgador ya que le impide que se exprese fuera del recinto de las deliberaciones: prohibición de fundamentar el veredicto". Aquí implica la apreciación del intérprete y el otorgamiento de facultades discrecionales al juzgador, quien aprecia la prueba libremente, sin estar atado a criterios legalmente preestablecidos.

Es propio del juez para obtener su íntima convicción valerse de los sentimientos, de las intuiciones, de las impresiones o de otros estados emocionales, de sus conocimientos personales; además de los razonamientos lógicos y de la experiencia. Dentro de este modelo, pueden identificarse a su vez dos variantes:

61 Jairo Parra Quijano, supra, nota 41. Pág. 215.

62 Id. Pág. 215. "No es posible, aun en el sistema de la tarifa legal, saber cuál es el valor que se le va a dar a la prueba antes de su valoración, pues puede suceder que los presupuestos que deben tenerse en cuenta para que sea plena no se den y, por tanto, otro sea el valor que resulte de la probanza recaudada. Así, por ejemplo, el artículo 697 del hoy derogado C.J. (Ley 105 de 1931) decía: 'Dos testigos hábiles que concuerden en el hecho y sus circunstancias de modo, tiempo y lugar, forman plena prueba en los casos en que este medio es admisible conforme a la ley"'.

64 Véase Jorge A. Clariá Olmedo. DERECHo PROCESAL PENAL. Rubinzal-Culzoni. (2008). 


\subsubsection{Sistema de apreciación en conciencia}

El que suele encontrarse en aquellos sistemas judiciales donde se halla presente la institución del "jurado", y en los que usualmente no existen normas que regulen la forma en que el material probatorio debe ser valorado ni la admisibilidad de cada evidencia en el juicio y en los cuales el juez debe dictar sentencia conforme con su prudencia y las pruebas rendidas en el proceso.

\subsubsection{Sistema de apreciación contra prueba}

En el cual el tribunal debe dictar sentencia únicamente de acuerdo con lo que su íntima convicción le indica, dejando de lado incluso las evidencias que las partes hubiesen aportado en el proceso, teniendo la posibilidad de que su fallo sea contrario a dichas probanzas"65

\subsection{Libre apreciación}

Para algunos sectores de la doctrina, este sistema también es conocido como la libre formación del convencimiento, apreciación razonada y libre convicción. Entre los autores más conocidos se ubica Paul Paredes, quien indica que "el sistema de la libre apreciación es aquel por el cual el juez mide la eficacia probatoria de cada medio de prueba, o de su conjunto, guiado por las reglas de la sana crítica, autoconformando su propia convicción que le permita sentar por ocurridos los hechos que representan los medios de prueba"66.

En este mismo sentido, indica el maestro Azula Camacho que "el sistema de libre apreciación consiste en dejar al juez la facultad de establecer el grado de convicción o credibilidad de cada medio probatorio y de todos en su conjunto, exponiendo, desde luego, los fundamentos de su conclusión"67. Por tanto, el juez es autónomo en la función de la valoración racional de la prueba, quien guiado y limitado por las reglas de la sana crítica, determina el valor o grado de convencimiento de la existencia de los hechos en controversia y motivando su razonamiento probatorio.

Aquí, el juez debe ser libre de apreciar los medios de prueba, según su propia razón, sin reglas previas que lo puedan constreñir a fallar en contra de su íntima persuasión, y en contra de lo que la ley sustantiva promete a los ciudadanos. Es decir, este método es la antítesis de la tarifa legal, por cuanto en esta, a priori, el legislador

\footnotetext{
65 Nadia Paz Jara Astudillo y Cristián Andrés Vigneaux Ramírez, supra, nota 18. Pág. 19.

66 Juan Linares San Román, supra, nota 49.

67 Jaime Azula Camacho, supra, nota 22. Pág. 64.
} 
establece cuál ha de ser el valor de cada medio probatorio que se allegue al proceso, tal como se dijo líneas atrás; y es más restringida que el de la íntima convicción, porque a pesar de la libertad que tiene el juez para apreciar las pruebas, no es absoluta, y aunque exista regulación en cuanto cuáles serán los medios de prueba o qué parte tendrá la carga de probar en cada caso, lo cierto es que bajo este modelo no existirán normas que determinen el valor probatorio que debe asignar el juez a cada evidencia. Justamente, este es el factor diferenciador entre los sistemas de valoración.

Sobre el particular, la Corte Constitucional comenta que en el caso de la sana crítica, como criterio adjunto a la libre valoración, necesariamente se produce por parte del funcionario un desapego de los perjuicios que puedan generar subjetividades o inclinaciones imparciales sobre cualquiera de las partes que participen de un proceso. ${ }^{68}$

\subsubsection{Ventajas del sistema}

Este sistema tiene las siguientes ventajas: "a. La crítica razonada de las pruebas la debe hacer el juez, lo que significa que no se trata de consagrar la arbitrariedad, sino de obligarlo al empleo de las reglas de la experiencia, de la lógica, de la historia, de la sicología, de la sociología, de la imaginación (la que también tiene sus reglas, para el caso del juzgador), para que en cada proceso administre justicia con más acierto, ya que valorará la prueba de acuerdo con lo dicho y para el caso concreto; b. el juez debe explicar en la parte motiva los razonamientos que hace sobre la prueba para cumplir con los principios de contradicción y de la debida defensa". ${ }^{99}$

\subsubsection{Características}

Los artículo 176 del CGP, el artículo 61 del CPTSS, el artículo 211 del CPACA y el artículo 380 del CPP "señalan las características del sistema de libre apreciación de la prueba, por tanto, los criterios que debe observar el juez, al cumplir su función son:

68 "Las reglas que rigen a la primera constituyen pautas diseñadas para estructurar el criterio de juzgamiento tomando como materiales para tal efecto la atmósfera o ambiente generado por un proceso determinado, los parámetros que le suministra al funcionario judicial tanto su propia experiencia como la experiencia histórica acumulada en la Administración de Justicia, y, en muchos casos, las reglas producidas en el proceso evolutivo de ciencias, técnicas y artes en los que se apoya la actividad judicial". Véase Corte Constitucional de Colombia. SENTENCIA C-222 de 1997 (MP José Gregorio Hernández Galindo; abril 29 de 1997).

Jairo Parra Quijano, supra, nota 41. 
la apreciación de las pruebas en conjunto, las reglas de la sana crítica"70 y la motivación razonada, el mérito que le asigne a cada prueba.

\section{Apreciación de las pruebas en su conjunto}

Esta característica, como atrás se señaló, es la manifestación del principio de la unidad de la prueba. Consiste en que el operador judicial debe analizar y evaluar la pluralidad de los medios probatorios en conjunto (artículos 176 del CGP, 61 del CPTSS, 211 del CPACA y 380 del CPP), como un todo, independientemente de la parte que la allegó o solicitó.

Téngase en cuenta que la prueba debe estar orientada al fin del proceso y no al movimiento de los intereses de las partes, partiendo de que la prueba hace una comunidad (principio de adquisición o comunidad de la prueba) ${ }^{71}$.

La Corte Suprema de Justicia considera que "la apreciación conjunta de la prueba consiste en la actividad intelectual que debe realizar juzgador de instancia analizando y conjugando los diversos elementos probatorios, y a través de la cual llega al convencimiento homogéneo, sobre el cual habrá de edificar su fallo estimatorio o desestimatorio: que son ciertas las alegaciones de hecho en que el demandante basa sus pretensiones o el demandado sus defensas; o que no lo son"72.

Que cumplan con los requisitos objetivos de la prueba, esto es, pertinencia, conducencia, utilidad y necesidad; que las pruebas no sean de aquellas que no estén prohibidas por la ley, y además que se hayan allegado y practicado en el proceso dentro las oportunidades probatorias y con observancia de los requisitos específicos de cada medio probatorio.

En esta apreciación, el operador judicial de manera regular y oportuna en su conjunto, sin entrar a distinguir entre cuáles son las aportadas por la parte demandante o por la parte demandada o en su defecto cuáles son las producidas oficiosamente.

70 Jaime Azula Camacho, supra, nota 22. Pág. 66.

71 Id. Pág. 66. Véase también Hernán Fabio López Blanco, supra, nota 22. Pág. 50.

72 Corte Suprema de Justicia. Sala de Casación Civil. Sentencia 14 de junio de 1982. Citada en: Corte Suprema de Justicia. SENTENCIA STC-21575 de 2017 (MP Luis Armando Tolosa; diciembre 15 de 2017). Disponible en: www.cortesuprema.gov.co/ corte/wp-content/uploads/ relatoría/tutela /B JUNIO2018/STC21575-2017.doc 


\section{La sana crítica}

La sana crítica $^{73}$ es una característica de la libre apreciación, también es una regla técnica de valoración de la prueba y es un criterio auxiliar para el juez; se define como "conjunto de reglas o criterios que distinguen y caracterizan el sistema de la libre apreciación".

También, se puede definir como "el conjunto de reglas que el juez debe observar para determinar el valor probatorio de la prueba, el cual se caracteriza por ser racional, en cuanto se ajusta a la razón o el discernimiento humano y es lógico por tener que enmarcarse dentro de las leyes del conocimiento"74.

En términos de Couture ${ }^{75}$, "las reglas de la sana crítica son reglas del correcto entendimiento humano; contingentes y variables en relación con la experiencia del tiempo, y del lugar; pero estables y permanentes en cuanto a los principios lógicos en que debe apoyarse la sentencia".

La sana crítica está integrada por elementos que contribuyen al ejercicio de la valoración, tales como las reglas de la experiencia, la lógica, la ciencia y la técnica.

\section{Elementos de la sana crítica}

El modelo de la sana crítica podemos ubicarlo como una opción que se encuentra entre el sistema de prueba legal y el de libre convicción en lo que se refiere a rigidez en la regulación y mayor libertad para el adjudicador, puesto que se trata de un modelo racional basado en que el juez, a la hora de valorar el material probatorio, debe hacerlo teniendo como guía y límite ciertos principios: las reglas de la lógica, las máximas de la experiencia y la ciencia. En este documento, solo se desarrollan las dos primeras.

Devis Echandía plantea que "el proceso moderno debe ser oral, aunque con ciertas restricciones como la demanda; inquisitivo para que el juez investigue

73 "Cuando se dice que las pruebas se apreciarán de conformidad con las reglas de la sana crítica, no se está haciendo referencia a una sujeción del juez a la ley (tarifa legal), que le establece el valor a la prueba, ni tampoco a una absoluta libertad que implicaría arbitrariedad, sino a una libertad reglada, ya que el juez debe tener en cuenta para valorar la prueba los excedentes extralegales que son: las reglas de la experiencia, las de la lógica, de la ciencia y de la técnica". Véase Jairo Parra Quijano. RAZONAMIENTO JUDICIAL EN MATERIA PROBATORIA. Biblioteca Jurídica Virtual del Instituto de Investigaciones Jurídicas de la UNAM. (s. f.). Pág. 1.

74 "Las disposiciones transcritas resaltan las características que distinguen la libre apreciación y los criterios que el juez debe observar al cumplir la función, que se encuentran en las siguientes: las reglas de la sana crítica y la apreciación es en conjunto". Véase Jaime Azula Camacho, supra, nota 22. Pág. 66.

75 Eduardo J. Couture. ESTUdIOS DEL DERECHO PROCESAL CIVIL. TOMO II. 2. ${ }^{\text {a }}$ edición. Ediciones Depalma. (1978). Págs. 193-195. 
oficiosamente la verdad, y con libertad de apreciar el valor de convicción de las pruebas según las reglas de la sana crítica basadas en los principios de la sicología y la lógica y las máximas generales de la experiencia, quedando sujeto únicamente a las formalidades que la leyes materiales contemplan ad substantiam actus, o sea solemnidades necesarias para la existencia o validez de ciertos actos o contratos"76.

Así las cosas, las reglas de la sana crítica son "pautas racionales fundadas en la lógica y la experiencia que hacen de la valoración judicial la emisión de un juicio formalmente válido (en tanto respeta las leyes lógicas del pensamiento) y argumentativamente sólido (en tanto apoyado en la experiencia apuntala la convicción judicial) que demuestra o repite, en los autos, la convicción formada en base a aquellas"77.

\section{Reglas de la experiencia}

Según Paul Paredes, son el "número de conclusiones extraídas de una serie de percepciones singulares pertenecientes a los más variados campos del conocimiento humano, tomadas por el juez como suficientes para asignar un cierto valor a los medios probatorios. Son reglas contingentes, variables en el tiempo y en el espacio, y están encaminadas a argumentar el valor probatorio asignado a cada medio probatorio en particular como, primordialmente, a su conjunto"78. Devis Echandía, sobre las reglas de la experiencia, precisa que no son objeto de prueba judicial,

[...] sino reglas para orientar el criterio del juzgador directamente (cuando son de conocimiento general y no requieren, por lo tanto, que se les explique, ni que se dictamine si tiene aplicación al caso concreto) o indirectamente a través de las explicaciones que le den los expertos o peritos que conceptúan sobre los hechos del proceso (cuando se requieren conocimientos especiales) [...] Es decir, esas reglas o máximas le sirven al juez para rechazar las afirmaciones del testigo, o la confesión de la parte, o lo relatado en un documento, o las conclusiones que se pretende obtener de los indicios, cuando advierte que hay contradicción con ellas, ya porque las conozca y sean comunes, o porque se las suministre el perito técnico ${ }^{79}$.

\footnotetext{
76 Jaime Azula Camacho, supra, nota, 22. Pág. 66.

77 Id.

78 Juan Linares San Román, supra, nota 49.

79 Id.
} 
En un estudio del profesor Parra Quijano de la UNAM, resalta que comprende las reglas de la experiencia, cuya fuente se origina en el "sentido común", el cual no es homogéneo ni determinado, pero permite al juez actuar de forma razonada cuando se presenta un acontecimiento que permita interactuar de manera teórico-práctica. ${ }^{80}$ De lo anterior, se deduce que el juez, en su construcción fáctico-jurídica, según el profesor Parra Quijano, debe:

a) Escrutar los hechos, con mucho cuidado.

b) Ensamblarlos en el campo de la imaginación.

c) Teniéndolos retenidos en la memoria e imaginando, debe juzgarlos utilizando como material para ello las reglas de la experiencia, la lógica, la ciencia y la técnica ${ }^{81}$.

De dicha reconstrucción se extrae, entonces, que en el uso de las reglas de la experiencia existe un mínimo de sentido común convergente en cualquier nivel de riesgo en la aplicación de la libre valoración, por lo que el elemento intersubjetivo es el llamado a garantizar la no desviación o arbitrariedad en la motivación de las decisiones judiciales.

Cabe decir que aunado a los criterios mencionados, la lógica, la ciencia y la técnica también permiten el razonamiento reglado del juez en el ámbito de la sana crítica, puesto que al igual que la libre valoración, existen mínimos de riesgo que en cierta medida pueden corromper o alterar el fundamento de las decisiones y en efecto ocasionar un régimen de valoración permeado por las libres y absolutas convicciones del juez; pues se trata de un escenario del que se pretende alejar al funcionario en su correcta y razonable manifestación.

Cuando se trata de reglas de la experiencia y sistema de libre valoración, el juez debe estimar que su labor no solo está dedicada a la práctica sustancial de la

80 "Como el sentido común, ese acervo o depósito en el cual vivimos y del cual nos valemos no se presenta ordenado y listo como un paquete que solo es abrir y aplicar su contenido, sino que debemos dentro de él extraer/decantar/exprimir la regla y en ese proceso ya debe haber racionalización, el itinerario podría ser: i) Aceptemos que en el sentido común, sin reflexionarlo, sin cuestionarlo, tenemos depositada la siguiente experiencia: las relaciones sexuales no consentidas dejan huellas materiales en la víctima. ii) Pero si tengo que aplicarla a un caso, la cuestiono y tengo que reflexionar sobre si es posible que se hayan dado relaciones sexuales no consentidas sin que existan golpes o rupturas de la ropa. iii) Puede suceder que haya una experiencia concreta que me haga cuestionar esa experiencia que tenía depositada en mi memoria. $\mathrm{K}$ es muy musculado y grande, al paso que la víctima es delgada y pequeña, y fue abordada de sorpresa". Véase Jairo Parra Quijano, supra, nota 73.

81 Id. 
norma, sino que está llamado a ser creador de derecho a través de los sistemas de interpretación y argumentación, considerando así no solo los aspectos básicos del proceso, sino también la valoración desde el punto de vista práctico y lógico.

El ejercicio de la valoración permite efectivizar los fines esenciales de la prueba, de tal manera que su función orientadora le otorga al juez los mínimos de certeza y de verdad a la hora de fundamentar las decisiones judiciales que, con motivo de los conflictos, generan unas exposiciones en derecho, sin dejar de lado el principio de unidad de la prueba.

\section{Las reglas de lógica}

Sustenta la validez formal del juicio de valor contenido en la resolución que emita el juez; permite evaluar si el razonamiento es formalmente correcto, es decir, si no se ha transgredido alguna ley del pensar. Sus características son su validez universal y la legitimación formal que le otorga a la valoración efectuada por el juez. Sobre el particular, Juan Monroy indica que se clasifica la lógica en analítica y dialéctica, la primera plantea que en un razonamiento, partiendo de afirmaciones necesariamente verdaderas, se llega a conclusiones que también deben ser verdaderas. Sobre la segunda, este autor precisa que estudia aquellos métodos que conducen el razonamiento en las discusiones o controversias, buscando persuadir, convencer o cuestionar la afirmación sostenida por el contrario ${ }^{82}$.

Las reglas básicas que a continuación se exponen son conocidas como principios:

a) Principio de contradicción

Nos dice que no se puede afirmar y negar una misma cosa respecto a algo al mismo tiempo. Se trata, entonces, de que dos enunciados que se oponen contradictoriamente no pueden ser ambos a la vez verdaderos.

b) Principio del tercio o tercero excluido

Establece que dos proposiciones que se oponen contradictoriamente no pueden ser ambas falsas. Así, tenemos que "si es verdadero que X es $A$, es falso que $X$ sea no $A^{\prime \prime}$. Entonces, se sostiene la verdad de una proposición y la falsedad de la otra proposición.

82 Juan Linares San Román, supra, nota 49. 
c) Principio de identidad

Mixan Mass sobre este principio dice: "En el proceso de raciocinio preciso todo concepto y juicio debe ser idéntico a sí mismo [...] Es, pues, inadmisible cambiar arbitrariamente una idea por otra, de hacerlo, se incurre en suplantación de concepto o de suplantación de tesis ${ }^{83}$.

d) Principio de razón suficiente

Es enunciado de la siguiente manera: "Nada es sin que haya una razón para que sea o sin que haya una razón que explique que sea". Esto es: "Ningún hecho puede ser verdadero o existente y ninguna enunciación verdadera sin que haya una razón suficiente para que sea así y no de otro modo"84. Se considera este principio como un medio de control de la aplicación de la libre apreciación de la prueba, pues se exige una adecuada motivación del juicio de valor que justifique la decisión del juez.

Actualmente en Colombia, en el derecho procesal impera el sistema de apreciación de la prueba basada en las reglas de la sana crítica (reglas de la experiencia y la lógica), consagrados entre otros artículos los siguientes: 176 del CGP, 60 y 61 del CPTSS, 211 del CPACA, 380 del CPP, los cuales fueron desarrollados en el apartado anterior.

\subsubsection{La motivación razonada: el mérito que el juez le asigna a cada prueba}

En conclusión, el sistema jurídico colombiano de manera expresa estableció los sistemas y reglas de valoración de la prueba según la materia del derecho (esto es, civil, laboral o penal). El juzgador al realizar su función de evaluar las pruebas obtenidas a través de los medios probatorios obrantes en autos, con el fin de verificar si las partes han acreditado sus afirmaciones o de esclarecer los hechos objeto de la controversia, no entró a definirlos, ni a desarrollarlos, por lo que el juez requiere acudir a las ciencias formales y a la ciencia fáctica para saber sus características, elementos, requisitos, etc.

A manera de conclusión, en este sistema el juez forma su libre convicción dando una explicación del porqué de su convencimiento respecto a algún medio o medios de prueba, con arreglo a las leyes de la ciencia, los principios de la lógica y las máximas de la experiencia, las cuales son expresadas en la sentencia pues en la

83 Id.

84 Id. 
parte considerativa de la misma debe figurar el proceso de convicción o certeza que las pruebas han creado en él, pues con ello se observarán los principios del debido proceso y del derecho de defensa.

Los sistemas de valoración de la prueba deberán ser considerados como unidades de medida que facilitan la libre determinación del juez en los casos en que su libre convicción pueda ser alterada por un falso raciocinio jurídico o falso raciocinio. De hecho, según se aprecie de manera errónea una norma o se aprecien de manera errónea las pruebas, en este último caso el juez debe observar las reglas de la sana crítica que evitan incurrir en un error de hecho o arbitrariedad o falso raciocinio, o quebrantamiento de la sana crítica. Así lo ha establecido la Corte Suprema de JusticiaSala de Casación Penal de Colombia que llama falso raciocinio a la mala aplicación que hace el juez de una regla de la experiencia, de la lógica, de la ciencia o de la técnica para valorar una prueba, porque en realidad la adecuación de la regla al caso supone no solamente extraerla del sentido común (en el caso de las reglas de la experiencia común), sino también razonarla y estrecharla para aplicarla al caso concreto"85.

\section{Estándar de prueba}

De lo anterior se deduce que el juez en su raciocinio jurídico, al apreciar la prueba en conjunto y exponer razonadamente el mérito que le asigne a cada prueba, obtuvo cierto grado de certeza o umbral de conocimiento suficiente, esto último conocido como estándar de prueba, que es lo que le permite tomar una posición respecto a la solución en concreto; verbigracia, en el área penal el juez debe poseer un conocimiento para condenar más allá de toda duda razonable, a posteriori, lo que la ley ha determinado estándar de prueba (artículo 381 del CPP).

\section{Concepto de estándar de prueba}

Según el Diccionario de la lengua española, "estándar" se define como "modelo, norma, nivel, guía, patrón o referencia"; y "prueba", para el contexto del presente escrito, es "razón, argumento, instrumento u otro medio con que se pretende verificar, confirmar o mostrar y hacer patente la verdad o falsedad de algo, o acreditar que aquello que se sabe y, por tanto, se afirma, corresponde exactamente a la realidad" 86 .

85 "Si se prefiere no utilizar la denominación de 'falso raciocinio', bastaría simplemente con decir que se trata de un error de hecho en la aplicación de la regla de la experiencia y se podrían utilizar los recursos en la forma que se indicó con anterioridad". Véase Jairo Parra Quijano, supra, nota 73.

86 Real Academia Española. Diccionario de la lengua española. 23. a edición. RAE. (2010). 
Ahora bien, al fusionar estas dos palabras, se puede entender que el estándar de prueba está concebido como un modelo, guía o patrón de referencia desde la prueba y que debe ser tenido en cuenta por el juez en relación directa con la demostración de los hechos, a fin de afirmar válidamente que un hecho de relevancia jurídica está probado desde el nivel de conocimiento establecido como parámetro por el legislador y que indudablemente permite producir un juicio o valor en la toma de la decisión razonable y argumentada ${ }^{87}$.

La doctrina y la jurisprudencia han sido fundamentales en el concepto de estándar de prueba, ya que en la legislación colombiana no se estipuló, salvo para el derecho penal, que se consagró como tal en el artículo 381 del Código de Procedimiento Penal (Ley 906 de 2004), el cual estipula que "para condenar se requiere el conocimiento más allá de toda duda".

\subsection{Concepto de estándar de la prueba desde la doctrina}

Las doctrinas de orden internacional y nacional coinciden al decir que el estándar de prueba es el nivel o grado de conocimiento necesario para poder tomar una decisión, por lo tanto, este juega un papel central y esencial dentro del razonamiento probatorio.

Entre los exponentes internacionales están:

- $\quad$ Taruffo ${ }^{88}$ expone que el estándar de prueba es un criterio que asiste al juez para que pueda elegir o preferir, de entre todas las hipótesis posibles que se tengan, aquella que se encuentre según su criterio más ajustado a la razón.

- Vásquez ${ }^{89}$ indica que: "El concepto de estándar de prueba surge del acto de valorar la prueba, de darle un peso demostrativo, o de asignarle validez por parte del juez (con respecto a la confirmación verdadera de uno o más hechos, materia de discusión en el proceso) a través del sistema de valoración adoptado".

- Larroucau90 plantea que puede considerársele como un "umbral que permite saber si un relato puede considerarse probado dentro de un proceso".

87 Lucero Ocampo Henao y Johana Catalina Restrepo Ramírez. EL ESTÁNDAR DE PRUEBA EN LoS PROCEsos administrativos sancionatorios. Maestría en Derecho Procesal, Universidad de Medellín-Universidad Católica del Oriente. (2018).

88 Michelle Taruffo, supra, nota 51.

89 Carmen Vásquez. ESTÁNDARES DE PRUEBA Y PRUEBA CIENTíFICA. ENSAYOS DE EPISTEMOLogíA JuRídiCA. Marcial Pons. (2013).

90 Jorge Larroucau Torres. Hacia un estándar de prueba civil. REVISTA CHILENA DE DERECHO 3. Diciembre 2012. Pág. 783. 
- $\quad$ Ferrer ${ }^{91}$ puntualiza que el estándar de prueba es un umbral a partir del cual se acepte una hipótesis como probada.

- Laudan ${ }^{92}$ define los estándares de prueba como los criterios que indican cuándo se ha conseguido la prueba de los hechos, son además los criterios que indican cuándo está justificado aceptar como verdadera la hipótesis del caso en particular. Precisa este autor que el estándar de prueba consiste en formular los criterios objetivos que indican cuándo se alcanza ese grado de probabilidad.

- Jordi Ferrer Beltrán" ${ }^{93}$ señala que "los estándares probatorios tienen su finalidad en establecer la veracidad o autenticidad de los hechos para alcanzar la justicia en las decisiones judiciales, lo que implica que se deberá implantar un umbral dentro del cual se aceptará una hipótesis como probada en el ejercicio de la valoración de las pruebas".

De lo anterior, el autor destaca que es necesario distinguir entre el hecho de lograr certezas razonables por medio de hipótesis y el hecho de no existir razones para elegir una u otra hipótesis. Sin dejar de contemplar que hoy en día, los criterios auxiliares de la valoración, tales como la ciencia, la química y la física, ofrecen una misma misión: la búsqueda de la verdad. ${ }^{94}$

Entre los exponentes colombianos están:

- Rúa95 identifica los estándares de prueba como los criterios que indican cuándo se ha conseguido la prueba de un hecho y cuándo está justificado aceptar como cierta determinada hipótesis.

91 Gabriel Real Ferrer. La solidaridad en el Derecho Administrativo. REVISTA DE ADMINISTRACIÓN PÚBLICA 161. Mayo-agosto 2003. Pág. 123.

92 Larry Laudan. VERDAD, ERROR Y PROCESO PENAL. Marcial Pons. (2013).

93 Gabriel Real Ferrer, supra, nota 91.

94 "Pese a que ambos tienen un objetivo en común, el cual es la búsqueda de la verdad, tienen grandes diferencias a señalar: la ciencia opera en tiempos largos, con recursos ilimitados y se orienta al descubrimiento de teorías generales o leyes, mientras que el proceso opera en tiempos restringidos, con recursos limitados y está orientado a producir una decisión definitiva sobre el objeto de la controversia; aun así ambos arrojan sus resultados en términos de probabilidades". Véase Natalia Vallejo Montoya, et al. APLICACIÓN DEL ESTÁNDAR DE PRUEBA POR LOS JUECES PROMISCUOS. Universidad Eafit. (2019). Disponible en http://www.eafit.edu.co/investigacion/semilleros/Documents/ estandar-prueba-jueces.pdf

95 Id. 
- Pinilla ${ }^{96}$ define el estándar de prueba como la pauta que le dice al juez cómo proceder cuando no se establezca, tras el proceso, un determinado grado de solidez de la hipótesis acusatoria con base en las pruebas válidamente aportadas.

\subsection{Concepto de estándar de prueba según la jurisprudencia colombiana}

- La Corte Constitucional, en Sentencia SU-636 de 2015, define el estándar como un umbral que le permite al juez determinar las razones fundadas para tomar una decisión.

- El Consejo de Estado lo define como el grado de conocimiento que le permite al juez determinar la existencia de un hecho o hipótesis en la que el juez sustenta la decisión (Sentencia-2362-12 de 2016).

- La Corte Suprema de Justicia ${ }^{97}$ define el estándar de prueba como: el grado de conocimiento requerido para la condena (certeza racional), que debe considerarse frente al hecho jurídicamente relevante que se integra al tema de prueba (el origen directo o indirecto de los bienes en alguna de las actividades ilícitas descritas en la norma), que puede lograrse con "prueba directa" o con "prueba indiciaria".

Como se puede apreciar, el concepto de estándar de prueba es pacífico tanto por la doctrina, como por la jurisprudencia, en tanto que lo califica como nivel de conocimiento al cual debe llegar el juez, pero dicho nivel debe estar en el plano de la menor posibilidad de subjetividad, con el fin de decidir racionalmente los conflictos de carácter jurídico.

\section{Clases de estándar de prueba}

Los estándares se pueden clasificar teniendo en cuenta el contexto y la naturaleza de la controversia. Claro que está en el proceso según los derechos y las garantías que se pueden afectar en las decisiones y según la aceptación doctrinal y jurisprudencial. Verbigracia, cuando la controversia es de carácter civil, utilizan el estado de prueba

96 Véase Ana María López Pinilla. Estándar de la prueba y defensas afirmativas en el proceso penal. Análisis con referencia al caso colombiano y español. NUEVo FORO PENAL 86. Enero-junio 2016. Pág. 151.

97 Corte Suprema de Justicia. SENTENCIA SP282-2017. Radicación 40120, Aprobado Acta N. ${ }^{\circ} 7$ (MP Patricia Salazar Cuéllar; enero 18 de 2017). 
de probabilidad prevalente, que se expresa en la formula "más probable que no" y en los sistemas de rasgo acusatorio; cuando es de asuntos delictivos, se manifiesta con "más allá de toda duda razonable".

Los estándares de prueba identificados para los autores de este texto son:

\subsection{Probabilidad preponderante o prevalente}

El estándar de prueba es denominado la regla de "más probable que no".

"Es un estándar de prueba que configura un criterio de decisión racional del juez al momento de fallar sobre los hechos, criterios que pretende racionalizar la discrecionalidad del mismo al corroborar el hecho teniendo en cuenta las pruebas que se allegan al proceso, y que no está establecido en norma alguna"98. Esto es, el estándar de la prueba se configura como la forma privilegiada para dar un contenido positivo al principio del libre convencimiento del juez, guiando y racionalizando la discrecionalidad del juez en la valoración de las pruebas, eliminando toda implicación irracional de esta valoración y vinculando al juez con la carga de criterios intersubjetivamente controlables.

El estándar de la probabilidad prevalente, como también es conocido por la doctrina, se funda en algunas premisas principales: a) Que se conciba la decisión del juez sobre los hechos como el resultado final de elecciones en torno a varias hipótesis posibles relativas a la reconstrucción de cada hecho de la causa; b) Que estas elecciones se conciban como si fueran guiadas por criterios de racionalidad; c) Que se considere racional la elección que toma como "verdadera" la hipótesis sobre hechos que resulta mejor fundada y justificada por las pruebas respecto a cualquier otra hipótesis; d) Que se utilice, como clave de lectura del problema de la valoración de las pruebas, no un concepto genérico de probabilidad como mera no-certeza, sino un concepto específico de probabilidad como grado de confirmación de la veracidad de un enunciado, sobre la base de los elementos de confirmación disponibles ${ }^{99}$.

La probabilidad prevalente configura un criterio de decisión racional del juez al momento de fallar sobre los hechos, criterio que pretende racionalizar la discrecionalidad del mismo al corroborar el hecho teniendo en cuenta las pruebas que se le alleguen al proceso, y que no está establecido en norma alguna, al menos en la mayoría de ordenamientos procesales, así como sucede en Colombia.

98 Natalia Vallejo Montoya, et al., supra, nota 94. 
Este estándar busca racionalizar y guiar la discrecionalidad del juez en la valoración de las pruebas, eliminando toda implicación irracional de esta valoración y vinculando al juez con la carga de criterios intersubjetivamente controlables.

Como se planteó líneas atrás, en algunos ordenamientos jurídicos se encuentra establecido en la ley o puede desprenderse de la normativa imperante, como ocurre por ejemplo en el caso de Estados Unidos; también existen muchos otros ordenamientos en que no existe ninguna norma expresa que haga referencia a este estándar y sin embargo se le entiende y aplica como un criterio de racionalidad mínima. Como es el caso colombiano que, a pesar de no estar contemplado en la Ley, es aplicado.

En el caso colombiano, no hay norma jurídica alguna que establezca esta clase de estándar, pero sí está desarrollado por la doctrina y jurisprudencia; verbigracia, la Corte Constitucional ha indicado que "no resultaba adecuado exigir la certeza de tal hecho, como lo hicieron los jueces de instancia, sino la demostración de la causa más probable [...] La causa más probable fueron los errores que cometió el médico al vendar el brazo con una presión excesiva, y al no tomar las medidas de precaución y seguimiento que prescribe la lex artis para evitar el resultado que se produjo"100.

\subsection{Estándar de evidencia clara y convincente}

Corresponde a un estándar probatorio intermedio, que puede situarse a medio camino entre el estándar de probabilidad prevaleciente y el estándar penal de "más allá de toda duda razonable". Este modelo de umbral probatorio exige al adjudicador, para dar por acreditada una determinada hipótesis sobre los hechos, que del material probatorio aportado por los litigantes pueda concluirse en forma categórica que es "mucho más altamente probable" que el hecho haya ocurrido a que no haya acontecido de una determinada forma ${ }^{101}$.

\subsection{Buena fe exenta de culpa}

La Ley 1448 de $2011^{102}$ entró a establecer una serie de medidas judiciales, administrativas, sociales, económicas, individuales y colectivas en beneficio de las víctimas

100 Corte Constitucional de Colombia. SENTENCIA T-074 de 2018 (MP Luis Guillermo Guerrero Pérez; marzo 2 de 2018). Disponible en: http://www.corteconstitucional.gov. co/relatoria/2018/t-074-18.htm

101 Nadia Paz Jara Astudillo y Cristián Andrés Vigneaux Ramírez, supra, nota 18. Pág. 3.

102 Ley 1448 de 2011. Por medio de la cual se dictan medidas de atención, asistencia, y reparación integral a las víctimas del conflicto armado interno. Junio 10 de 2011. Do 48.096. 
dentro de un marco de justicia transicional, que posibilite hacer efectivo el goce de sus derechos a la verdad, la justicia y la reparación con garantía de no repetición ${ }^{103}$.

Entre las medidas de reparación a víctimas del conflicto armado interno está la restitución de tierras de los despojados y desplazados (artículos 60 a 87); de igual manera, contempla la figura de las oposiciones, con el fin de que las personas que tengan derechos legítimos relacionados con el predio objeto de restitución los hagan valer, así como quienes se consideren afectados por el proceso de restitución (como mecanismo de defensa-derecho de contradicción, artículo 88).

El inciso 3 del artículo 88 (Oposiciones)104 establece que: "Al escrito de oposición se acompañarán los documentos que se quieran hacer valer como prueba de la calidad de despojado del respectivo predio, de la buena fe exenta de culpa, del justo título del derecho y las demás pruebas que pretenda hacer valer el opositor en el proceso".

Por su parte, el inciso 1 del artículo 91 de la misma disposición (Contenido del Fallo) señala que: "La sentencia se pronunciará de manera definitiva [...] y decretará las compensaciones [...] a favor de los opositores que probaron la buena fe exenta de culpa dentro del proceso. Así como el literal dispone las órdenes necesarias para garantizar que las partes de buena fe exenta de culpa vencidas en el proceso sean compensadas cuando fuera del caso, en los términos establecidos por la presente ley".

Y el inciso 1 del artículo 98 (Pago de las Compensaciones) estipula que: "El valor de las compensaciones que decrete la sentencia a favor de los opositores que probaron la buena fe exenta de culpa dentro del proceso, será pagado por el Fondo de la Unidad Administrativa Especial de Gestión de Restitución de Tierras Despojadas".

Estos artículos tienen como criterio común "la buena fe exenta de culpa", el cual debe ser valorado por los jueces, así como frente a segundos ocupantes de predios objeto de restitución que demuestren condición de vulnerabilidad y no hayan tenido relación directa o indirecta con el despojo ${ }^{105}$

A efectos de este documento, solo se establecerá el significado del estándar buena fe "exenta de culpa". La buena fe es un principio reconocido constitucionalmente cuya función es integradora del ordenamiento y reguladora de las relaciones

103 Id. Artículo 3.

104 Corte Constitucional de Colombia. SENTENCIA T-119 de 2019 (MP Antonio José Lizarazo Ocampo; marzo 18 de 2019). Disponible en: http://www.corteconstitucional.gov.co/relatoria/2019/T-119-19.htm

105 Corte Constitucional de Colombia. SENTENCIA C-330 de 2016 (MP María Victoria Calle Correa; julio 23 de 2016). Disponible en: http://www.corteconstitucional.gov.co/relatoria/2016/C-330-16.htm 
entre particulares, y entre estos y el Estado (artículo $83 \mathrm{CP}$ ). Así las cosas, tanto el derecho constitucional como el civil han desarrollado, además del concepto de buena fe, como mandato constitucional general, la figura de la buena fe simple como principio y forma de conducta. Esta "equivale a obrar con lealtad, rectitud y honestidad, es la que se exige normalmente a las personas en todas sus actuaciones". El Código Civil, al referirse a la adquisición de la propiedad, la define en el artículo 768 como "la conciencia de haberse adquirido el dominio de la cosa por medios legítimos, exentos de fraude y de todo otro vicio". Esta buena fe se denomina simple, por cuanto si bien surte efectos en el ordenamiento jurídico, estos solo consisten en cierta protección que se otorga a quien así obra.

Por otro lado, la Corte Constitucional ${ }^{106}$, con respecto a la buena fe cualificada o exenta de culpa, ha explicado:

Esta buena fe cualificada tiene la virtud de crear una realidad jurídica o dar por existente un derecho o situación que realmente no existía. La buena fe creadora o buena fe cualificada interpreta adecuadamente una máxima legada por el antiguo derecho al moderno: 'error communis facit jus', y que ha sido desarrollada en nuestro país por la doctrina desde hace más de cuarenta años, precisando que: "Tal máxima indica que si alguien en la adquisición de un derecho o de una situación comete un error o equivocación, y creyendo adquirir un derecho o colocarse en una situación jurídica protegida por la ley, resulta que tal derecho o situación no existen por ser meramente aparentes, normalmente y de acuerdo con lo que se dijo al exponer el concepto de la buena fe simple, tal derecho no resultará adquirido. Pero si el error o equivocación es de tal naturaleza que cualquier persona prudente y diligente también lo hubiera cometido, por tratarse de un derecho o situación aparentes, pero en donde es imposible descubrir la falsedad o no existencia, nos encontramos forzosamente ante la llamada buena fe cualificada o buena fe exenta de toda culpa".

106 Id. Artículo 87. Véase también Corte Constitucional de Colombia. SENTENCIA C-740 de 2003 (MP Jaime Córdoba Triviño; agosto 28 de 2003); reiterada en la SENTENCIA C-795 de 2015 (MP Jorge Iván Palacio Palacio; octubre 30 de 2015). 
Ahora bien, en relación con la buena fe exenta de culpa en materia de restitución de tierras, circunda la acreditación de actuaciones positivas encaminadas a consolidar dicha certeza ${ }^{107}$, lo cual lleva a que los terceros sean merecedores de la compensación.

\subsection{Conocimiento más allá de toda duda razonable}

El estándar de prueba de conocimiento, "más allá de toda duda razonable", consiste en limitar la discrecionalidad valorativa y la inferencia de la prueba con base en la aplicación y observancia de los criterios de la sana crítica.

Así las cosas, es imperioso que el juzgador efectúe un análisis profundo de toda la actividad de valoración de la prueba, desde la escogencia de los medios de prueba en los que se cimienta el fallo, hasta el razonamiento utilizado para condenar, es decir, permitiendo formar su convencimiento más allá de toda duda razonable, sobre la ocurrencia de los hechos y circunstancias materia del juicio y los de la responsabilidad penal del acusado, tal como lo estipula el artículo 372 del CPP.

Por lo anterior, este estándar de prueba requiere de una rigurosa precisión, ya que en el ámbito penal se pretende demostrar culpabilidad. En ese sentido, es crucial entender la lógica de la interacción entre el estándar de prueba y el beneficio de la duda108.

Al respecto, la jurisprudencia de la Corte Suprema de Justicia, en su Sala de Casación Penal ${ }^{109}$, ha vinculado el estándar de prueba con el necesario respeto por el principio de presunción de inocencia y el sistema de valoración de la prueba respaldado en la sana crítica, es decir, desde las reglas de la lógica, reglas de la experiencia y leyes de la ciencia.

\subsection{Certeza más allá de toda duda razonable}

Este estándar fue afirmado por el Consejo de Estado (Sentencia 2362-12 del 06 de octubre de 2016 - Sala de lo Contencioso Administrativo, sección 2, subsección 2 CP, Sandra Lisset Ibarra), bajo el criterio de que este estándar de prueba implica que la certeza de una hipótesis solo es viable cuando se eliminen totalmente la viabilidad de otras. Que la hipótesis que sustenta la decisión debe ser única y no admite otras aun

107 Id. Artículo 88.

108 Corte Suprema de Justicia. SENTENCIA SP282-2017. Radicación 40120 (Aprobado Acta

N. ${ }^{\circ}$ ) (MP Patricia Salazar Cuéllar; enero 18 de 2017).

109 Id. 
cuando sean probables, pues ese estándar de certeza implica que estas hayan sido eliminadas completamente.

Una de las preocupaciones en el estudio del "estándar de prueba" es considerarlo como una actividad problemática, dado que su aplicación puede ocasionar cierta arbitrariedad por parte del juez, porque los factores que condicionan la validez, la certeza y sobre todo la valoración de la prueba resultan necesarios al momento de emitir juicios de valor, y para ello es necesario la noción de estándar de prueba, concepto que remite a la identificación de los elementos de validez necesarios para que exista certeza sobre un juicio; sin embargo, este concepto abarca toda una serie de problemáticas de índole doctrinal-jurídica, tales como la objetividad de esos estándares, así como la existencia de los mismos.

\section{Valoración de la prueba y estándar de prueba. Dos conceptos distintos pero relacionados}

La ley procesal colombiana (artículo 164 CGP) ${ }^{110}$ plantea que los jueces deben sustentar y motivar sus decisiones (sentencia) conforme a las pruebas regular y debidamente allegadas al proceso, acatando la apreciación de la prueba en conjunto, de acuerdo con las reglas de la sana crítica y exponiendo razonadamente el mérito que le asigne a cada prueba (sistema de valoración) (artículos 176 CGP; 61 CPTSS; 211 CPACA; 380 CPP), porque son estos los presupuestos o características que le van a permitir alcanzar cierto grado de certeza o umbral de conocimiento (estándar de prueba).

Teniendo en cuenta la anterior afirmación, los resultados que pueden alcanzarse mediante la actividad probatoria solo pueden expresarse en términos de certeza o probabilidad, y es precisamente en este punto del razonamiento probatorio cuando entran en juego dos conceptos distintos, pero relacionados.

El primero es la valoración de la prueba, que se definió como "un proceso intelectual realizado por el juez y mediante el cual busca extraer, en la medida de lo posible, la verdad existente detrás de los medios de prueba incorporados en la causa"111; en otras palabras, se refiere a la determinación del apoyo empírico que los elementos de prueba aportados proporcionan a las hipótesis sobre los hechos del caso que se enfrentan en el proceso ${ }^{112}$. Y el segundo es el estándar de prueba, es decir, el nivel de certeza que debe alcanzar el juez para poder dar por verdadero ciertos presupuestos

110 Corte Constitucional de Colombia. SENTENCIA T-289 de 2003 (MP Manuel José Cepeda Espinosa; abril 4 de 2003). Disponible en: http://www.corteconstitucional.gov.co/relatoria/2003/T-289-03.htm

111 Roberto van Hasselt Garrido, supra, nota 45. Pág. 213.

112 Daniela Accatino, supra, nota 46. Pág. 485. 
fácticos sostenidos por las partes dentro del proceso, o como lo define Larroucau: "umbral que permite saber si un relato puede considerarse probado dentro de un proceso"113.

Como se puede apreciar, estos dos conceptos son diferentes en su definición, pero se encuentran íntimamente relacionados; enmarcados dentro del proceso intelectual razonado, pero desarrollándose en momentos diferentes. Por ejemplo, la valoración, en estricto sentido, corresponde al momento previo en que el juez trata de determinar cuál es la mayor o menor fuerza probatoria de los medios de prueba, como si de alguna manera pesaran estas evidencias.

En este momento, el juez procede a la "determinación del apoyo empírico que los elementos de juicio aportados al proceso proporcionan a las hipótesis en conflicto, de forma individual y en conjunto"114

Por otro lado, el estándar de prueba opera en un momento posterior y si se quiere, en el momento final de la actividad valorativa, en que el juez se vale de este instrumento para decidir si según el peso de las diversas pruebas, ya determinado con anterioridad, y según los diversos grados de corroboración que dichas pruebas otorgaron a las hipótesis fácticas sostenidas por las partes, se puede considerar alcanzado un nivel de suficiencia necesario para dar por probados los hechos en la forma planteada por uno de los litigantes ${ }^{115}$.

Por último, hay que tener en cuenta que a pesar de ser conceptos distintos, ambos responden a la misma racionalidad del acervo probatorio, con observancia a razonamientos y criterios objetivos controlables. Por tal razón, un estándar de prueba adecuadamente construido no solo determinará el nivel de probabilidad que debe superarse para estimar suficientemente la evidencia, sino que además debe constituirse como una guía para el juez al momento de valorar la prueba, en el sentido de explicitar las evidencias que el juzgador debe buscar para justificar su decisión, de manera que no quede espacio a subjetividades. Como lo ha señalado la Corte Constitucional,

[...] si bien el juzgador goza de un amplio margen para valorar el material probatorio en el cual ha de fundar su decisión y formar libremente su convencimiento, inspirándose en los principios científicos de la sana crítica, dicho poder jamás podrá ejercerse de manera arbitraria; su actividad evaluativa probatoria implica, necesariamente, la adopción de criterios objetivos, no simplemente supuestos por el juez, racionales, es decir,

113 Jorge Larroucau Torres, supra, nota 90. Pág. 783.

114 Daniela Accatino, supra, nota 46. Pág. 351.

115 Nadia Paz Jara Astudillo y Cristián Andrés Vigneaux Ramírez, supra, nota 18. Pág. 19 
que ponderen la magnitud y el impacto de cada una de las pruebas allegadas, y rigurosos, esto es, que materializan la función de administrar justicia que se les encomienda a los funcionarios judiciales sobre la base de pruebas debidamente recaudadas.176

Al respecto, la Dra. Marina Gascón señala que los estándares de prueba son objetivos en la medida en que los esquemas de valorización mantengan un contenido racional, es decir que los mismos prevean cierto grado de confirmación, interactuando primero por la valoración y luego por la justificación. La idea de formar estándares de prueba objetivos busca en cierta medida evitar la subjetividad, como sucede en el caso de la íntima convicción, dado que no se trata de un estándar que ostente un criterio controlable.117

Esta misma autora, refiriéndose a estándares de prueba objetivos relacionados con las probabilidades y sus criterios, indica que estos deben ser:

1. Máximas de la experiencia.

2. La calidad epistemológica de las pruebas confirmatorias, es decir, si se tiene la hipótesis A y la hipótesis no A.

3. Evaluar la calidad epistemológica de las pruebas que confirmen una hipótesis.

4. Número de pasos inferenciales, es decir, el número de inferencias que se deban hacer para llegar a una conclusión, esto es, si se llega directamente o se debe hacer un razonamiento muy largo para obtener la conclusión.

5. Cantidad y variedad de las confirmaciones, si se tienen varias pruebas que confirman la misma conclusión por distintos caminos, entonces tiene un alto grado de valor probabilístico en términos de esa probabilidad inductiva y no probabilidad matemática.

6. Articulación de los mismos, son los que le permiten al juez resolver el conflicto allegado a su conocimiento por las partes.

116 Corte Constitucional de Colombia. SENTENCIA T-104 de 2014 (MP Jorge Iván Palacio Palacio; febrero 26 de 2014).

117 "Los estándares probatorios se insertan, pues, en un proceso de valoración racional. Más exactamente cumplen dos funciones. Una función heurística primero: el estándar es el criterio conforme al cual deberá el juez formular su valoración final sobre los hechos de la causa. Y una función justificadora después (en cuanto criterios para la motivación): el estándar es el criterio conforme al cual ha de reconstruirse la justificación de la decisión probatoria". Marina Gascón Abellán, supra, nota 47. 
Lo anterior permite concluir que a pesar de que la valoración de la prueba y la aplicación del estándar de prueba corresponden a dos momentos distintos, ambos responden a la misma racionalidad del razonamiento probatorio y deseablemente, a criterios objetivos y controlables; razón por la que un estándar de prueba adecuadamente construido no solo determinará el nivel de probabilidad que debe superarse para estimar suficiente la evidencia, sino que además debe constituirse como una guía para el juez al momento de valorar la prueba, en el sentido de explicitar las evidencias que el juzgador debe buscar para justificar su decisión, de manera que no quede espacio para decisiones discrecionales subjetivas y arbitrarias.

\section{E. Resultados}

La información recaudada arrojó:

(I) los jueces de diferente naturaleza aplican de manera preponderante el sistema de la libre apreciación/sana crítica) sobre los otros dos sistemas de valoración;

(II) los jueces de diferente naturaleza, para llegar a la certeza, utilizan la lógica y las reglas de la experiencia como elementos de la sana crítica;

(III) la Ley Procesal Probatoria (legislación civil, laboral, administrativa y penal) contempla expresamente el sistema de libre apreciación de la prueba "sana crítica";

(IV) la Ley Procesal Probatoria expone los elementos integradores de la sana crítica; pero para su aplicación es necesario acudir a la jurisprudencia y a la doctrina como fuentes auxiliares de la actividad judicial (artículo 230 CP), toda vez que se guardó silencio respecto a los criterios a considerar;

(v) en cuanto al estándar de prueba, el derecho procesal probatorio en materia civil, laboral y contencioso administrativo no lo contempla; entre tanto, la ley procesal penal, en capítulo de pruebas, lo incorpora expresamente, estableciendo que el juez al momento de condenar requiere del conocimiento "más allá de duda razonable"; y en restitución de tierras, relacionado con el segundo ocupante, es necesario probar "la buena fe exenta de culpa";

(vI) igual que con la valoración de la prueba, es necesario recurrir a la jurisprudencia y a la doctrina como fuentes auxiliares de actividad judicial por ser normas vacías; 
(VII) si bien la norma procesal y los jueces manifiestan aplicar el sistema de valoración de sana crítica y como elementos prevalentes aplican reglas de la experiencia y la lógica, esto no se ve reflejado en las decisiones;

(VIII) los jueces manifiestan no conocer los estándares de prueba a aplicables a los procesos civiles, laborales y contenciosos administrativos;

(IX) en materia de restitución de tierras y en penal es obligatorio la aplicación del estándar establecido en la Ley 1448 de 2011 y en la Ley 906 de 2004, en sus decisiones se evidencian la aplicación de los mismos;

(x) Los estándares probatorios son un tema novedoso y poco abordado en Colombia.

\section{F. Conclusiones centrales sobre los sistemas de valoración y los estándares probatorios}

Si bien los conceptos de valoración y estándar de prueba difieren en su definición, ellos se encuentran íntimamente relacionados, pudiendo enmarcarse ambos dentro del proceso intelectual de valoración probatoria entendido en general, pero desarrollándose en momentos distintos dentro del proceso.

Cuando se habla de sistemas de valoración de la prueba, corresponde al momento previo, en que el juzgador trata de determinar cuál es la mayor o menor fuerza probatoria de los medios de prueba aportados, como si de alguna forma "pesara" estas pruebas, estableciendo en atención al mayor o menor peso de las mismas la probabilidad de que las hipótesis fácticas sustentadas por las partes sean verdaderas.

Para el caso en particular de estudio, el estándar de prueba opera en un momento posterior y si se quiere, en el momento final de la actividad valorativa. De ahí que el estándar de prueba es el instrumento del que se vale el juez para decidir si de acuerdo con el peso de las diversas pruebas, ya determinado con anterioridad, y según los diversos grados de corroboración que dichas pruebas otorgaron a las hipótesis fácticas sostenidas por las partes, se puede considerar alcanzado un nivel de suficiencia necesario para dar por probados los hechos en la forma planteada por las partes.

Quiere decir, entonces, que los dos momentos mencionados se encuentran directamente ligados durante el proceso judicial o administrativo sancionatorio, y que la articulación de los mismos es lo que le permite al juez resolver el conflicto allegado a su conocimiento por las partes. 
Según el sondeo que se realizó en los juzgados municipales de FlorenciaCaquetá de naturaleza civil, laboral y penal, esto es, a través de entrevistas semiestructuradas y principalmente de opinión, se pudo evidenciar que la mayoría de los jueces en el momento de la valoración de la prueba, tal y como se realiza al momento de dictar sentencia, no son conocedores de los sistemas de valoración en efecto de los estándares probatorios.

Lo anterior es debido a que resulta complejo aplicar el estándar probatorio a la hora de dictar la decisión judicial en temas civiles principalmente (casi desconocido), y en derecho penal es un término que se introdujo al sistema jurídico colombiano a principios de la expedición del nuevo Código Penal (Ley 599 de 2000). Es sumamente preocupante que los jueces de nuestra región, específicamente en el territorio de la ciudad de Florencia, no logren distinguir su concepto y sus ámbitos de aplicación dado que no solo contemplan procesos de especialidad, sino que existen distintos procesos dada su naturaleza.

Se concluye que de forma meramente cualitativa, los jueces en la ciudad de Florencia-Caquetá realizan la valoración de la prueba sin distinguir los conceptos y los casos en concreto de aplicación. Es decir, la valoración es un mero acto formal que no contempla criterios, reglas o una forma clara de realizar la misma.

El ejercicio de la valoración y la aplicación de los estándares probatorios son de compleja aplicación, pero no eximen de su responsabilidad a los jueces, quienes son los encargados directos de aplicar e interpretar la norma en ocasiones excepcionales.

El Ilamado que aquí pretenden los autores es necesario dada la precaria situación con que los jueces aplican los sistemas de valoración. Durante las entrevistas, se logró evidenciar que también existe una grave confusión entre lo que aquí se expone como sana crítica y la libre apreciación de las pruebas en conjunto; la misma situación se presenta entre la íntima convicción y la libre apreciación, dos sistemas totalmente diferentes y con elementos que permiten identificar o resolver en la medida del derecho los conflictos que surgen en la sociedad.

\section{REFERENCIAS}

Ana Giacomette Ferre. PARA LOGRAR LA TUTELA JURISDICCIONAL EFECTIVA EN LA PRUEBA EN LOS PROCESOS CONSTITUCIONALES. 2. ${ }^{a}$ edición. Señal Editorial y Ediciones Uniandes. (2009).

Ana María López Pinilla. Estándar de la prueba y defensas afirmativas en el proceso penal. Análisis con referencia al caso colombiano y español. Nuevo Foro Penal 86. Enero-junio 2016. Pág. 151. 
Carmen Vásquez. ESTÁNDARES de PRUEBA Y PRUEBA CIENTíFICA. ENSAYOS DE EPISTEMOLOGíA JURÍDICA. Marcial Pons. (2013).

Daniela Accatino. Certezas, dudas y propuestas en torno a estándar de prueba penal. REVISTA DE Derecho de La Pontificia Universidad Católica de Valparaíso 48. 2011.

Decreto 2158 de 1948. Por medio del cual se expide el Código Procesal del Trabajo y de la Seguridad Social sobre procedimientos en los juicios de trabajo. Julio 24 de 1948. Do 26773; modificado por la Ley 712 de 2001, del 8 de diciembre de 2001. DO 44. 680.

Decreto-Ley 2158 de 1948. Por medio del cual se expide el Código Procesal del Trabajo y la Seguridad Social. Modificado por la Ley 712 de 2001. Diciembre 8 de 2001. DO 44.640.

Eduardo J. Couture. Fundamentos Del DeRECHO PRocesal CIVIL. 3. ${ }^{\text {a }}$ edición. Roque Depalma Editores. (1958).

Eduardo J. Couture. Estudios del DeRECho PROCESAL CIVIL. TOMO II. 2. ${ }^{\text {a }}$ edición. Ediciones Depalma. (1978).

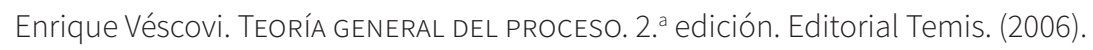

Gabriel Real Ferrer. La solidaridad en el Derecho Administrativo. REVISTA DE ADMINISTRACIÓN PÚBLICA 161. Mayo-agosto 2003. Pág. 123.

Hernán Fabio López Blanco. Código general del proceso. Pruebas. Dupre Editores. Ltda. (2017).

Hernando Devis Echandía. Teoría general de LA PRUeba Pericial. Biblioteca Jurídica Diké. (1987).

Hernando Devis Echandía. Compendio de LA PRUEBA Judicial. Tomo I. Rubinzal-Culzoni Editores. (2000).

Jaime Azula Camacho. Manual de DeReCho PRocesal. Tomo VI. Pruebas Judiciales. 4. a edición. Editorial Temis. (2017).

Jairo Iván Peña Ayazo. PRUebA JUdICIAL: ANÁlISIS YVALORIZACIÓN. Consejo Superior de la Judicatura, Escuela Judicial Rodrigo Lara Bonilla. (2008).

Jairo Parra Quijano. MANUAL DE DERECHO PROBATORIO. 10. ${ }^{a}$ edición. Librería Ediciones del Profesional Ltda. (1999). 
Jairo Parra Quijano. MANUAL DE DERECHO PROBATORIO. 18. ${ }^{a}$ edición. Librería Ediciones del Profesional Ltda. (2011).

Jairo Parra Quijano. RazonAmIEnTO JUdICIAL En MATERIA PROBATORIA. Biblioteca Jurídica Virtual del Instituto de Investigaciones Jurídicas de la UNAM. (s. f.).

Juan Linares San Román. LA valoración de LA PRUEBA. Blog Derecho y Cambio Social. (s. f.). Disponible en: http://www.derechoycambiosocial.com/revista013/laprueba.htm.

Jorge Cardozo Isaza. PRuebaS JUdicIALES. 4. ${ }^{a}$ edición. Ediciones Librería del Profesional. (1982).

Jorge Larroucau Torres. Hacia un estándar de prueba civil. Revista ChILENA de DeRECHO 3. Diciembre 2012.

Larry Laudan. VERDAD, ERROR Y PROCESO PENAL. Marcial Pons. (2013).

Leonel Gustavo Cáceres. El falso RACIOCINIO, QUebrantAmIENTO DE LA SANA CRÍTICA. Ediciones Jurídicas Gustavo Ibáñez Ltda. (2005).

Marina Gascón Abellán. PRUebA JUdiCIAL: VALORACIÓN RACIONAL Y MOTIVACIÓN. Universidad de Castilla-La Mancha. (2012). Disponible en: http://www.uclm.es/posgrado.derecho/02/web/ materiales/filosofia/Prueba.pdf

Michele Taruffo. ALGUNAS CONSIDERACIONES SOBRE LA RELACIÓN ENTRE PRUEBA YVERDAD. LA PRUEBA. Editorial Metropolitana. (2008). Disponible en: http://letrujil.files.wordpress.com/2012/01/ la-prueba-michele-taruffo.pdf

Nadia Paz Jara Astudillo y Cristián Andrés Vigneaux Ramírez. ESTÁNDAR DE PRUEBA EN EL PROCESO CIVIL. ESTUDIO SOBRE LOS TIPOS DE ESTÁNDAR DE PRUEBA Y SU NECESIDAD EN EL FUTURO PROCESO CIVIL CHILENO. Trabajo de grado. Universidad de Chile. (2017).

Natalia Vallejo Montoya, et al. Aplicación del ESTÁNDAR de PrUebA POR LOS JUECES Promiscuos. Universidad Eafit. (2019). Disponible en http://www.eafit.edu.co/investigacion/semilleros/ Documents/estandar-prueba-jueces.pdf

Ley 906 de 2004. Por medio de la cual se expide el Código de Procedimiento Penal. Septiembre 1 de 2004. DO 45.658.

Ley 1448 de 2011. Por medio de la cual se dictan medidas de atención, asistencia, y reparación integral a las víctimas del conflicto armado interno. Junio 10 de 2011. Do 48.096. 
Ley 1437 de 2011. Por la cual se expide el Código de Procedimiento Administrativo y de lo Contencioso Administrativo. Julio 2 de 2011. DO 47.956.

Ley 1564 de 2012. Por medio de la cual se expide el Código General del Proceso. Julio 12 de 2012. DO 48.489 .

Lucero Ocampo Henao y Johana Catalina Restrepo Ramírez. EL ESTÁNDAR DE PRUEBA EN LOS PROCESOS ADMINISTRATIVOS SANCIONATORIOS. Maestría en Derecho Procesal, Universidad de Medellín-Universidad Católica del Oriente. (2018).

Óscar Eduardo Henao Carrasquilla. CódIgo general DEL PROCESO. ANOTADo. Editorial Leyer. (2017).

Real Academia Española. Diccionario de la lengua española. 23. ${ }^{a}$ edición. RAE. (2010).

Roberto van Hasselt Garrido. EL ESTÁNDAR DE PRUEBA EN MATERIA INFRACCIONAL. ANÁLISIS JURISPRUDENCIAL. Centro de Estudios Tributarios Universidad de Chile. (2015).

Ugo Rocco. TRatado de dereCho procesal CIVIL. Tomo I. Editorial Depalma. (1996). 